(C) 2016, Elsevier. Licensed under the Creative Commons Attribution-NonCommercial-NoDerivatives 4.0 International

http://creativecommons.org/licenses/by-nc-nd/4.0/

\title{
Eco-Efficiency considering the issue of Heterogeneity among Power Plants
}

\author{
Behrouz Arabi ${ }^{1}$, Susila Munisamy ${ }^{2}$, Ali Emrouznejad ${ }^{3 *}$, Mehdi Toloo $^{4}$, Mohammad Sadegh \\ Ghazizadeh $^{5}$ \\ ${ }^{1}$ Institute of Graduate Studies, University of Malaya, Kuala Lumpur, Malaysia, beh.arabi@um.edu.my \\ ${ }^{2}$ Faculty of Economics and Administration, University of Malaya, Malaysia, susila@um.edu.my \\ ${ }^{3}$ Aston Business School, Aston University, Birmingham, UK \\ ${ }^{4}$ Faculty of Economics, Technical University of Ostrava, Ostrava, Czech Republic, mehdi.toloo@ vsb.cz \\ ${ }^{5}$ Department of Electrical Engineering, Abbaspour School of Engineering, Shahid Beheshti University, Tehran, \\ Iran, Ghazizadeh@pwut.ac.ir
}

\begin{abstract}
One of the main objectives in restructuring power industry is enhancing the efficiency of power facilities. However, power generation industry, which plays a key role in the power industry, has a noticeable share in emission amongst all other emission-generating sectors. In this study, we have developed some new Data Envelopment Analysis models to find efficient power plants based on less fuel consumption, combusting less polluting fuel types, and incorporating emission factors in order to measure the ecological efficiency trend. We then applied these models to measuring eco-efficiency during an eight-year period of power industry restructuring in Iran. Results reveal that there has been a significant improvement in eco-efficiency, cost efficiency and allocative efficiency of the power plants during the restructuring period. It is also shown that despite the hydro power plants look eco-efficient; the combined cycle ones have been more allocativeefficient than the other power generation technologies used in Iran.
\end{abstract}

Keywords: Data Envelopment Analysis, Power Plants, Eco-Efficiency, Restructuring, Malmquist Luenberger, Slacks-Based Model

\section{Introduction}

A number of achievements such as "technological improvements, better services, higher efficiency, improved reliability, as well as less costly delivery of electricity to customers" are

\footnotetext{
* Corresponding Author: Ali Emrouznejad, Aston Business School, Aston University, Birmingham, UK, a.emrouznejad@aston.ac.uk
} 
expected from power industry restructuring (Bulent Tor and Shahidehpour, 2005; Khosroshahi et al., 2009). As a developing country, Iran started restructuring its power industry since 1990 (Khosroshahi et al., 2009). Ghazizadeh has enumerated improvement in efficiency as one of the two most important objectives of restructuring the Iranian power industry (Ghazizadeh et al., 2007). Therefore, to see the effects of restructuring, it is of necessity to measure and report the efficiency of power facilities.

On the other hand, according to the Third, Fourth and Fifth "National Development Plan of the Islamic Republic of Iran" (hereafter, we refer to as NDP-IR), the government is mandated to observe sustainability. As a matter of fact, sustainable development has three aspects: social, economic, and environmental development (Scott Cato, 2009). The environmental development has two prime requirements: environment has to be protected and natural resources have to be exploited in an optimal way. These two criteria are required to be incorporated in every efficiency measurement system to reflect the real system. Thus, the expression 'ecological efficiency' -or in brief, eco-efficiency - has been coined to reflect efficiency measures incorporating ecological effects of an industrial activity. Eco-efficiency has different definitions, but Schaltegger and Sturm (1990, p. 240) define eco-efficiency as the ratio of economic value creation to environmental impact added. Hence, to see the restructuring achievements, eco-efficiency measurement, rather than efficiency measurement, is inevitable.

In a power industry, power generation plays a critical role not only from economic aspects but also from the environmental ones. In addition to polluting water, power plants consume huge amounts of oil products and generate a huge amount of emissions at the same time. Initial National Communication to UNFCC $2010^{*}$ revealed that the energy sector had a $77 \%$ share of $\mathrm{CO} 2$ emissions in 2007 in Iran. Whereas energy generation industries produce 33\% of all CO2 emissions amongst energy sub-sectors. This illustrates that power generation industry has an indispensable contribution to the countrywide emission. Hence, the primary aim of this study is to measure the eco-efficiency trend of power plants for an eight-year period of the Iranian power industry restructuring from 2003, when the power market, as one the most effective modules of restructuring, started.

\footnotetext{
* http://unfccc.int/2860.php, retrieved 10/65/2015
} 
Data Envelopment Analysis (DEA) is one of the well-recognized approach using for measuring efficiency and productivity of Decisions Making Units (DMUs) (Emrouznejad et al., 2014. DEA has widely been adopted by many researchers to evaluate energy efficiencies (Han et al., 2015; Khoshroo et al., 2013; Lee et al., 2013; Li and Lin, 2015; Song et al., 2013; Wang, 2015). One can find numerous power plant eco-efficiency studies using DEA in the literature (Arabi et al., 2016; Athanassopoulos et al., 1999; Färe et al., 2006; Golany et al., 1994; Sueyoshi and Goto, 2011). However, to sketch the complete picture, non-homogeneous power plants should be included in the assessment, too. This is necessary for the policymakers to see which technology has performed more productive technically, environmentally friendly, cost efficiently consuming fuel, and capital in optimally to generate more, yet pollute less. However, in a heterogeneous set of power plants, this study is not straightforward.

Conventional DEA is conducted under homogeneity assumption. This assumption refers to the similarity of DMU under assessment; this problem has named 'homogeneity pitfall' (Dyson et al., 2001). Homogeneity pitfall has different forms such as when DMUs employ different technologies. However, the most severe form occurs when DMUs use different inputs or produce different outputs (employing different technologies is not of importance). In this paper, a comprehensive productivity analysis is conducted by measuring the cost and allocative efficiencies in addition to the eco-efficiency. This enables the researchers to compare different power generation technologies from different efficiency perspectives so that they can provide proper decision support reports for future investments, budgeting, and planning purposes.

Moreover, whereas restructuring almost shows its effects on the rules and regulations related to the power industry, in this study, rather than the conventional methods, the restructuring rules for calculating the input or output factors, on the exact exercising date is deployed. For example, contrary to the majority of previous studies, the fuel cost is calculated by taking into account the charges made for extra use or incentives for optimal consumption of fuels. This exhibits direct effects of the restructuring on the performance.

The rest of the paper comes in the following order. A literature review of restructuring power industry and environmental issues of power generation in Iran is presented in Sections 2. Section 3 gives a brief introduction of DEA and directional distance function (DDF), then introduces an approach for handling heterogeneity amongst power plants when different efficiency indexes are 
measured. Section 4 presents conceptual models for eco-efficiency and cost efficiency indices and discusses input and output selection. Results of the research are delineated graphically in section 5. A detailed discussion of the results with some policy recommendation is given in Section 5.2. Finally, the paper is closed by a brief conclusion and suggesting a direction for future research.

\section{Background}

\subsection{Power industry restructuring and green electricity production in Iran}

Iran started a reform in its power industry in early 1990's (Ghazizadeh et al., 2007; Khosroshahi et al., 2009). A new interpretation of the $44^{\text {th }}$ Article of Islamic Republic of Iran's Constitution paved the way for the power industry to establish Iranian Grid Management Company (IGMC) in 2003. This allows for private sector investment in new power generation facilities*, privatization of $10 \%$ of the current generation capacity each year, and restructuring of Tavanir, Iran's specialized holding company for power generation, transmission and distribution management.

Similar to what was done in several other countries, vertical integration of generation, transmission, distribution and retailing utilities was broken down in three steps. Financial separation by detaching their accounting systems, establishment of every utility as an independent legal entity (except for the transmission sector, which is a natural monopoly and must remain in the government's ownership according to the new interpretation of Article 44 of Islamic Republic of Iran's Constitution), and IGMC providing all market participants with open access to the national grid (Ghazizadeh et al., 2007). By taking these three steps, according to (Ghazizadeh et al., 2007), the two following objectives were pursued by the leaders and planners of the electricity sector restructuring:

1. "It is expected that the restructuring and consequently privatization improve the performance and efficiency of the present industry";

2. "It is expected that the development of a new competitive paradigm in the electricity industry could make the sector more attractive for potential independent investors."

\footnotetext{
* Third NDP-IR, Paragraph b of Article 122-1998
} 
The power market was inaugurated in October 2003 to promote the competition; firstly, for the power plants to sell their energy to IGMC under a pay-as-bid regime; secondly, for the distribution companies to purchase their demanded energy. Preliminary studies for establishment of an electricity stock market are also being conducted by the power market regulatory board. By capacity payment policy, power plants are encouraged to keep their available capacity at a maximum level in order to keep up a reasonable reserve margin of the national grid. These are all supported by the "executive bylaw of guaranteed electricity purchase mechanism and conditions", subject of the Clause "b" of Article (25), of the Fourth, validated by the Fifth NDP-IR. By Article 9 of the same bylaw, to encourage consumption of a cleaner and cheaper fuel, (natural) gas was determined as the main fuel for thermal power plants, and marginal price difference of gas and alternative fuel (liquid fuels including Gasoil and Fuel oil, which are more expensive than natural gas) was decided to be paid back if they happened to have no choice but to consume liquid fuels as alternative.

According to Article 10 of the same bylaw, green electricity generation is also supported by payments for nonpolluting and as equivalent to fuel that has not been combusted to generate the same amount of energy as a thermal power plant with the national grid average of the Yield Factor. To support green electricity, "Executive Bylaw for Guaranteed Wholesale Electricity Mechanisms and Conditions in the Iranian National Grid" also mandates IGMC to buy the electricity generated by renewable energy power plants, whenever they happen to be available or have to generate electricity. This happens, for example, when a hydro power plant has to open the sluice to irrigate its downstream*.

Further, since the power market's official inauguration date, in October 2003, Iran power market regulatory board has ratified many procedures and instructions to conduct the process of the reform. A number of these acts, which determine the formulas for calculation of the awards and charges, will be addressed later in Section 4. Next section explores environmental issues of the power generation industry in Iran.

\footnotetext{
${ }^{*}$ The conditions and mechanisms have been stipulated in Article 6-6 of the same bylaw.
} 


\subsection{Environmental issues of the power generation industry in Iran}

As a result of industrial development, exploitation of natural resources increases and the environment is exposed to more pollutants. Thus, if a developing country does not prevent, occurrence of natural crises, the environment will be unavoidably endangered thereafter. Similar to many other developing countries, Iran has also decided to pay full attention to the environmental issues. According to Initial National Communication to UNFCC 2010, the energy industries in Iran account for a noticeable share of $\mathrm{CO} 2$ emissions, amounting to $33 \%$ in 2007. According to the country's energy balance sheet in annual reports, power generation sector has produced 192,733 tons of SO2 in 2005 with further increase of 497,354 in 2009. This is while the contribution of power plants to $\mathrm{SO} 2$ production amongst all energy industries has increased from $23.01 \%$ to $36.68 \%$ during the same period*. Moreover, the emission rate for each $\mathrm{kWh}$ of electricity generated is demonstrated in the following graph:

\section{[Figure 1 - about here]}

As can be observed in Figure 1, although the amount of $\mathrm{SO} 2$ per kWh of generated electricity declined in the last two years and $\mathrm{CO} 2$ per kWh of generated electricity decreased slightly in 2010, the trend lines still show a steep slope. Similar trends can also be observed for CO and NOX.

Mazandarani et al. (2011) showed from another perspective that the emission by power generation industry would have been controlled by 2025 through the promotion of green electricity technologies. They predicted that although power generation installed capacity will increase by $215.75 \%$ from 2010 to 2025 , the emission would grow almost at a similar rate.

In addition to the laws and regulations cited already in this paper, Iranian government ratified several other regulations to ensure reduction of emissions. For the first example: Article 15 of the Air Pollution Prevention Act which determines the maximum allowed amount of emission to be produced by all polluting industries, including power plants. In addition, Articles 104, 121 and 134 of the Third NDP-IR (2000), validated and extended to the fourth and fifth NDP-IR (2004 and 2009), which emphatically mandates reduction of fuel consumption and emissions by all means.

\footnotetext{
* Iran's Energy Balance Sheet Annual Reports, 2005 and 2009
} 
In the instructions attached to this executive bylaw, the mechanism for calculation of charges to be imposed on the industrial units, which exceed the allowed emission amount has been stipulated.

\section{Methodology}

In order to measure the eco-efficiency, in this study, non-parametric frontier based method of DEA is deployed. To observe different efficiency measures such as eco-efficiency, cost efficiency, and allocative efficiency a series of DEA Slacks-Based Models (SBM) are introduced and employed to calculate Malmquist and Malmquist Luenberger indexes. In this section, homogeneity pitfall in DEA is also addressed and a solution to handle this issue in the power plants case is introduced.

\subsection{Data Envelopment Analysis (DEA)}

The non-parametric frontier based efficiency was initially introduced by Farrell (1957). Charnes et al. (1978) formulated this concept as a linear programming model, assuming constant returns to scale (CRS) the first DEA model introduced in this paper now is well-known as CCR. Later this model was extended by Banker et al. (1984) to include the assumption of variable returns to scale (VRS). Since then many other DEA models have been developed including weight restrictions (Dyson and Thanassoulis, 1988), super efficiency (Andersen and Petersen, 1993).

DEA is a mathematical optimization methodology to evaluate the efficiency of a group of homogeneous DMUs. Consider $N$ DMUs are using $I$ similar inputs to produce $J$ similar outputs. Let $\boldsymbol{x}_{n}=\left(x_{1 n}, \ldots, x_{I n}\right) \in \mathbb{R}^{I}$ and $\boldsymbol{y}_{n}=\left(y_{1 n}, \ldots, y_{I n}\right) \in \mathbb{R}^{J}$ be semi-positive input and output vectors corresponding to $D M U_{n}$, respectively, such that $n=1, \ldots, N$. Then, consider $\boldsymbol{X}_{n}=$ $\left(\boldsymbol{x}_{1}, \ldots, \boldsymbol{x}_{I}\right)_{I \times N}$ and $\boldsymbol{Y}_{n}=\left(\boldsymbol{y}_{1}, \ldots, \boldsymbol{y}_{I}\right)_{J \times N}$ to be input and output matrices. Let $\boldsymbol{u}$ and $\boldsymbol{v}$ be semipositive vector with $J$ and $I$ components, respectively. Then $\boldsymbol{w}=\left[\begin{array}{l}\boldsymbol{u} \\ \boldsymbol{v}\end{array}\right]$ is called virtual multiplier or weight vector, in which $\boldsymbol{w}$ is named $D$-proper if (1) $\boldsymbol{u}^{T} \boldsymbol{y}_{n}>0$ for at least one $n$, (2) $\boldsymbol{v}^{T} \boldsymbol{x}_{n}=0$ for all $n$ if $\boldsymbol{u}^{T} \boldsymbol{y}_{n}=0$. We call the collection of such multiplier as multiplier space and denote it by $W$. Now for $\boldsymbol{w} \in W$ and $n=1, \ldots, N$, we define:

$$
h_{n}(\boldsymbol{w})=\left\{\begin{array}{lr}
\frac{\boldsymbol{u}^{T} \boldsymbol{y}_{n}}{\boldsymbol{v}^{T} \boldsymbol{x}_{n}} & \boldsymbol{v}^{T} \boldsymbol{x}_{j}>0 \\
\text { undefined } & \boldsymbol{u}^{T} \boldsymbol{y}_{n}=\boldsymbol{v}^{T} \boldsymbol{x}_{n}=0
\end{array}\right.
$$


We call this 'the ratio of outputs to inputs for the collection of multipliers' (weights). Using the method proposed in Charnes and Cooper (1967) this fractional programming can be transferred to the following linear programming problem, named as CCR (Charnes, Cooper and Rhodes, 1978). Model (2a) is an input oriented version of CCR, in which it tries to find the maximum possible reduction of inputs while keeping the output level constant.

$$
\begin{aligned}
& \max f=\sum_{j} y_{j o} u_{j} \\
& \text { s. t. } \\
& \sum_{i} x_{i o} v_{i}=1 \\
& \sum_{j} y_{j n} u_{j}-\sum_{i} x_{i n} v_{i} \leq 0, \quad n=1, \ldots, N \\
& u_{j}, v_{i} \geq 0 \quad j=1, \ldots, J ; i=1, \ldots, I
\end{aligned}
$$

where $\boldsymbol{u}=\left(u_{1}, \ldots, u_{J}\right)$ and $\boldsymbol{v}=\left(v_{1}, \ldots, v_{I}\right)$ are weights with respect to each output and input respectively.

Similarly, an output-oriented version of CCR model can be presented in Model (2b) in which it tries to find the maximum possible increase of outputs while keeping the input level constant.

$$
\begin{aligned}
& \max f=\sum_{j} x_{j o} v_{j} \\
& \text { s.t. } \\
& \sum_{i} y_{i o} u_{i}=1 \\
& \sum_{j} y_{j n} u_{j}-\sum_{i} x_{i n} v_{i} \leq 0, \quad n=1, \ldots, N \\
& u_{j}, v_{i} \geq 0 \quad j=1, \ldots, J ; i=1, \ldots, I
\end{aligned}
$$

A comprehensive procedure for Non-parametric Projects have been described in (Emrouznejad and De Witte, 2010). The theory of DEA has been picked by researchers and have been developed to various other models, for example the most productive scale size (Banker, 1984), Malmquist index (Fare et al., 1989), Selective Measures ( Toloo and Tichý, 2015), Malmquist Leunberger index (Chung et al., 1997).

In the present study, Malmquist Leunberger Index (MLI) is deployed to measure the eco-efficien cychange of Iranian power plants. We begin our study with Directional Distance Function (DDF) as introduced by Chung et al. (1997). 


\subsection{Directional distance function and slacks-based measures}

In some cases, inorder to deal with efficiency measurement issue, one may face unwanted input or output factors, which have a non-ignorable effect on the efficiency. In the literature, this type of factors is recognized as undesirable. In this study, for example, emission and deviation from generation plan are undesirable factors. A number of different models have been presented to incorporate undesirable factors in the DEA models such as using the additive inverse of undesirable factors (Berg et al., 1992), treating an undesirable output as an input (Tyteca, 1997a), using multiplicative inverse (Knox Lovell et al., 1995), hyperbolic efficiency model (Boyd and McClelland, 1999), slacks-based measure (SBM) (Tone, 2001), Range Adjusted Measure (RAM) (Zhou et al., 2006), and DDF which is one of the most popular model introduced to incorporate undesirable or bad factors. In this section, the concentration is on DFF and SBM, which are presented below.

Let $\boldsymbol{b} \in \mathbb{R}^{K}$ be the bad outputs of DMU's or equivalently $\boldsymbol{b}_{n}=\left(b_{1 n}, b_{2 n}, \ldots, b_{K n}\right)$ be the bad outputs of $\mathrm{DMU}_{n}$. If $I, J$, and $K$ are the number inputs, outputs, and bad outputs. $P(\boldsymbol{x})$, production possibility set, is redefined as:

$$
P(\boldsymbol{x})=\left\{(\boldsymbol{y}, \boldsymbol{b}): \boldsymbol{x} \in \mathbb{R}^{I} \text { can produce }(\boldsymbol{y}, \boldsymbol{b}) \in \mathbb{R}^{J+K}\right\}
$$

In addition, Chung et al. (1997) defined $D$ as:

$$
D(\boldsymbol{x}, \boldsymbol{y}, \boldsymbol{b} ; \boldsymbol{g})=\sup \{\theta:(\boldsymbol{y}, \boldsymbol{b})+\theta \boldsymbol{g} \in P(\boldsymbol{x})\}
$$

where $\boldsymbol{g} \in \mathbb{R}^{J+K}$ is a direction vector that can be written as $\left(g_{y 1}, \ldots, g_{y J}, g_{b 1}, \ldots, g_{b K}\right)$ and $\theta$ denotes expansion or contraction proportion of the good and bad outputs. Using directional distance function, $D$, under free disposability ${ }^{*}$ and null-jointness ${ }^{\dagger}$ assumptions, we expand the good outputs, in direction $\boldsymbol{g}$, while simultaneously contract the bad outputs, in the same direction. Accordingly, Chung et al. (1997) formulated the efficiency measurement with both good and bad outputs as follows:

\footnotetext{
${ }^{*}(\boldsymbol{y}, \boldsymbol{b}) \in P(x)$ and $\boldsymbol{y}^{\prime} \leq \boldsymbol{y}$ imply $\left(\boldsymbol{y}^{\prime}, \boldsymbol{b}\right) \in P(x)$.

+ if $(\boldsymbol{y}, \boldsymbol{b}) \in P(x)$ and $\boldsymbol{b}=\mathbf{0}$ then $\boldsymbol{y}=\mathbf{0}$, this explains the condition that good and bad outputs are jointly produced.
} 


$$
\begin{array}{ll}
D_{o}(\boldsymbol{x}, \boldsymbol{y}, \boldsymbol{z})=\max \theta & \\
\text { s.t. } & i=1,2, \ldots, I \\
\sum_{n=1}^{N} \lambda_{n} x_{i n} \leq x_{i o} ; & j=1,2, \ldots, J \\
\sum_{n=1}^{N} \lambda_{n} y_{j n} \geq y_{j o}+g_{y j} \cdot \theta ; & j=1,2, \ldots, K \\
\sum_{n=1}^{N} \lambda_{n} z_{k n}=z_{k o}-g_{b k} . \theta ; & k=1 \\
\sum_{j=1}^{J} g_{y j}+\sum_{k=1}^{K} g_{z k}=1 & \\
\theta \geq 0 ; \lambda_{n} \geq 0 ; g_{y j} \geq 0 ; & n=1,2, \ldots, N ; j=1,2, \ldots, J ; \\
g_{z k} \geq 0 ; & k=1,2, \ldots, K
\end{array}
$$

The last constraint, which neither changes the production possibility set nor directions, is included into the model to scale the directions to fall within the interval $[0,1]$. It is easy to verify that Model (5) can be transformed to the following slacks-based model by incorporating bad outputs as indicated in Färe and Grosskopf (2010a); Färe and Grosskopf (2010b)*:

$$
\begin{array}{ll}
D_{o}(\boldsymbol{x}, \boldsymbol{y}, \boldsymbol{z})=\max \sum_{j=1}^{J} \beta_{j}+\sum_{k=1}^{K} \gamma_{k} & \\
\text { s.t. } & i=1,2, \ldots, I \\
\sum_{n=1}^{N} \lambda_{n} x_{i n} \leq x_{i o} ; & j=1,2, \ldots, J \\
\sum_{n=1}^{N} \lambda_{n} y_{j n} \geq y_{j o}+\beta_{j} .1 ; & k=1,2, \ldots, K \\
\sum_{n=1}^{N} \lambda_{n} z_{k n}=z_{k o}-g_{b k} . \theta ; & \\
\sum_{j=1}^{J} g_{y j}+\sum_{k=1}^{K} g_{z k}=1 & n=1,2, \ldots, N ; j=1,2, \ldots, J ; \\
\theta \geq 0 ; \lambda_{n} \geq 0 ; g_{y j} \geq 0 ; & j=1,2, \ldots, J ; k=1,2, \ldots, K \\
\beta_{j} \geq 0 ; \gamma_{k} \geq 0 ; g_{z k} \geq 0 ; &
\end{array}
$$

Also, further developments of slacks-based models can be found in Färe et al. (2015); Fukuyama et al. (2014). A two-dimensional version of Model (6) is presented in Ramli et al. (2013) and further details can be found in Arabi et al. (2014) and Arabi et al. (2015). Model (6) can be customized for other purposes, for example, to obtain a model which emphases more on input preservation and less emission production with the same output production, Model (6) can be written as below:

\footnotetext{
${ }^{*}$ This can easily be verified if one takes $g_{y j} \cdot \theta=\beta_{j} \& g_{z k} \cdot \theta=\gamma_{k}$
} 


$$
\begin{array}{ll}
D_{o}(\boldsymbol{x}, \boldsymbol{y}, \mathbf{z})=\max \sum_{l=1}^{L} \underline{\alpha}_{l}+\sum_{h=1}^{H} \bar{\alpha}_{h}+\sum_{m=1}^{M} \alpha_{m}+\sum_{k=1}^{K} \gamma_{k} \\
\text { s.t. } & \\
\sum_{n=1}^{N} \lambda_{n} \underline{x}_{l n} \leq \underline{x}_{l o}+\underline{\alpha}_{l} .1 & l=1,2, \ldots, L \\
\sum_{n=1}^{N} \lambda_{n} \bar{x}_{h n} \leq \bar{x}_{h o}-\bar{\alpha}_{h} .1 & h=1,2, \ldots, H \\
\sum_{n=1}^{N} \lambda_{n} x_{n} \leq x_{m o}-\alpha_{m} .1 & m=1,2, \ldots, M \\
\sum_{l=1}^{L} \underline{\alpha}_{l}-\sum_{h=1}^{H} \bar{\alpha}_{h}=0 & \\
\sum_{n=1}^{N} \lambda_{n} y_{j n} \geq y_{j o} & j=1,2, \ldots, J \\
\sum_{n=1}^{N} \lambda_{n} z_{k n}=z_{k o}-\gamma_{k} .1 & k=1,2, \ldots, K \\
\lambda_{n} \geq 0 ; \underline{\alpha}_{l} \geq 0 & n=1,2, \ldots, N ; l=1,2, \ldots, L \\
\bar{\alpha}_{h} \geq 0 ; \alpha_{m} \geq 0 ; \gamma_{k} \geq 0 & h=1,2, \ldots, H ; m=1,2, \ldots, M ; k=1,2, \ldots, K
\end{array}
$$

where, $\bar{x}=\left(\bar{x}_{1}, \ldots, \bar{x}_{N}\right)$ and $\underline{x}=\left(\underline{x}_{1}, \ldots, \underline{x}_{N}\right)$ denote high and low pollutant inputs, determined by the magnitude of their pollutant part and $x$ represents the nonpolluting inputs such as capital. As such $\bar{\alpha}=\left(\bar{\alpha}_{1}, \ldots, \bar{\alpha}_{H}\right)$ and $\underline{\alpha}=\left(\underline{\alpha}_{1}, \ldots, \underline{\alpha}_{L}\right)$ are defined as the rate of contraction and expansion of high and low pollutant inputs respectively and $\alpha=\left(\alpha_{1}, \ldots, \alpha_{M}\right)$ is rate of contraction in nonpolluting inputs. Also, $\bar{\alpha}_{n}$ and $\underline{\alpha}_{n}$ are the pollutant part of high and low pollutant inputs, respectively; it is evident that $\bar{\alpha}_{n}>\underline{\alpha}_{n}$ and if $\bar{\alpha}_{n}=\underline{\alpha}_{n}$ there is no need to distinction between high and low pollutants. Consequently, we should have $H+L+M=I$, that is the total number of inputs. We also included $\sum_{l=1}^{L} \underline{\alpha}_{l}-\sum_{h=1}^{H} \bar{\alpha}_{h}=0$ to the model to guarantee that the same level of the fuel is delivered to the turbines generate the same electricity as output Otherwise, there is a possibility for all fuel input types to get zero which is practical.

In the next section, we take this concept to MLI as well as cost and allocative efficiency change when data is available over time.

\subsection{Different productivity indexes and heterogeneity amongst power plants}

Although Cobb and Douglas (1928) considered capital and labor as the factors of production, many others such as Kurz and Salvadori (1997) added land to the compound of capital and labor. These are not the only main factors of production that have been presented in the production theory. This is while new growth theory takes the technology as a factor of production (Aghion and Howitt, 1997; Cornwall and Cornwall, 1994). In so doing, heterogeneity amongst power plants is highlighted, particularly when the objective of the study is to compare different power plants in terms of their productivity. 
Hydro power plants in this research are treated as a special case, since a hydro power plant neither consumes fuel nor does it produce any emissions. Therefore, in nature, they use one less input (fuel) to produce one less bad output (emission). In fact, they consume zero fuel, to produce zero emission. Although this may increase their eco-efficiency in comparison with the thermal power plants, it also reflects the reality of green electricity that is generated by this type of power plant.

Furthermore, different power plant technologies have different prices. The depreciation of the facilities employed by a power plant, successfully proxies the difference amongst the technologies used. By cost efficiency analysis, we depict which type of power plant pays less to generate the same level of electricity.

Finally, by evaluating allocative efficiency, we exhibit which type of power plants, from the cost point of view, allocated the proportions of inputs to produce the same level of outputs more successfully.

In the next section, we present the indices of productivity and productivity changes and discuss how these factors enable the researcher to perform/draw a comprehensive comparison between the firms performing similar jobs using different technologies.

\subsubsection{Malmquist Luenberger index and cost and allocative efficiency changes}

To examine the productivity of the different power plants from all perspectives, observing the cost and allocative efficiency seems to be necessary. Toward this end, we define good input and bad output requirements set as $L^{t}\left(\boldsymbol{y}^{t}\right)=\left\{\left(\boldsymbol{x}^{t}, \boldsymbol{z}^{t}\right)\right.$, where $\boldsymbol{x}$ can produce $\boldsymbol{y}$ together with $\left.\boldsymbol{z}\right\}$. If $C^{t}\left(\boldsymbol{x}^{t}, \mathbf{z}^{t}, \boldsymbol{w}^{t}\right)=\min _{\left(\boldsymbol{x}^{t}, \mathbf{z}^{t}\right) \in L^{t}\left(\boldsymbol{y}^{t}\right)}\left\{\sum_{i=1}^{I} w_{x_{i}}^{t} x_{i}^{t}+\sum_{k=1}^{K} w_{z_{k}}^{t} z_{k}^{t}\right\}$ indicates the minimum possible cost to produce $\boldsymbol{y}^{t}$, in period $t$, where $w_{x_{i}}^{t}$ is the cost of one unit of the $i^{t h}$ input consumed and $w_{z_{k}}^{t}$ is the fine should be paid for one extra unit of the $k^{t h}$ bad output produced in the period $t$. Farrell (1957) defines the cost efficiency as the ratio of the minimum possible cost to the actual cost, which is formulated in many studies (Ball et al., 2005; Jahanshahloo et al., 2007; Maniadakis and Thanassoulis, 2004; Mostafaee and Saljooghi, 2010) as follows:

$$
C E^{t}=\frac{c^{t}\left(x^{t}, z^{t}, w^{t}\right)}{c^{t}}
$$


where $C E^{t}$ denotes cost efficiency in the period $t$ and $c^{t}=\sum_{i=1}^{I} c_{i}^{t}\left(x_{i}^{t}\right)+\sum_{k=1}^{K} c_{k}^{t}\left(z_{k}^{t}\right)$ indicates the actual cost in period $t$, in which $c_{i}^{t}\left(x_{i}^{t}\right)$ is actual cost of the $i^{t h}$ input and $c_{k}^{t}\left(z_{k}^{t}\right)$ is actual fine being paid for the $k^{t h}$ bad output in the period $t$. In addition, under the weak disposability conditions, we use the following model to calculate minimum possible cost:

$$
\begin{array}{ll}
C^{t}\left(\boldsymbol{x}^{t}, \boldsymbol{z}^{t}, \boldsymbol{w}^{t}\right)=\min _{x^{t}, z^{t}} \sum_{i=1}^{I} w_{x i}^{t} x_{i}^{t}+\sum_{k=1}^{K} w_{z k}^{t} z_{k}^{t} \\
\text { s.t. } & i=1,2, \ldots, I \\
\sum_{n=1}^{N} \lambda_{n} x_{i n}^{t} \leq x_{i}^{t} & j=1,2, \ldots, J \\
\sum_{n=1}^{N} \lambda_{n} y_{j n}^{t} \geq y_{j o}^{t} & k=1,2, \ldots, K \\
\sum_{n=1}^{N} \lambda_{n} z_{k n}^{t}=z_{k}^{t} & \\
\sum_{i=1}^{I} H V_{i}^{t} x_{i n}^{t}=\sum_{i=1}^{I} H V_{i}^{t} x_{i o}^{t} & \\
\lambda_{n} \geq 0 & n=1,2, \ldots, N
\end{array}
$$

where $\sum_{i=1}^{I} H V_{i}^{t} x_{i n}^{t}=\sum_{i=1}^{I} H V_{i}^{t} x_{i o}^{t}$ guarantees the minimum heating value needed to generate $y_{j o}^{t}$ is supplied to the turbines. Without this constraint, all $x_{i n}^{t}$ for fuel inputs can get zero value, which is impossible in real world, it is obvious for thermal power plants no fuel combustions means no electricity generation.

In addition, (Fried et al., 2008) define allocative efficiency as the ratio of the cost efficiency to the input-oriented measure of technical efficiency, if based on Chung et al. (1997) the technical efficiency is formulated as:

$$
T E^{t}=\frac{1}{1+D_{o}^{t}\left(\boldsymbol{x}^{t}, \boldsymbol{y}^{t}, \mathbf{z}^{t}\right)}
$$

Using the equations (8) and (10), we write the allocative efficiency formula as follows:

$$
A E^{t}=\frac{C E^{t}}{T E^{t}}=\frac{C^{t}\left(\boldsymbol{x}^{t}, \mathbf{z}^{t}, \boldsymbol{w}^{t}\right)\left(1+D^{t}\left(\boldsymbol{x}^{t}, \boldsymbol{y}^{t}, \mathbf{z}^{t}\right)\right)}{c^{t}}
$$

According to Ball et al. (2005); Edvardsen et al. (2006); (Granderson and Prior, 2013), the cost efficiency change is defined as:

$$
C E F F C H_{t}^{t+1}=\frac{C E^{t+1}}{C E^{t}}=\frac{C^{t+1}\left(x^{t+1}, z^{t+1}, w^{t+1}\right)}{C^{t}\left(\boldsymbol{x}^{t}, \mathbf{z}^{t}, \boldsymbol{w}^{t}\right)} \frac{c^{t}}{c^{t+1}}
$$

And the cost technical efficiency change is defined as: 


$$
C T E C H_{t}^{t+1}=\left[\frac{C^{t}\left(\boldsymbol{x}^{t+1}, \mathbf{z}^{t+1}, \boldsymbol{w}^{t+1}\right)}{C^{t+1}\left(\boldsymbol{x}^{t+1}, \mathbf{z}^{t+1}, \boldsymbol{w}^{t+1}\right)} \frac{C^{t}\left(\boldsymbol{x}^{t}, \mathbf{z}^{t}, \boldsymbol{w}^{t}\right)}{C^{t+1}\left(\boldsymbol{x}^{t}, \mathbf{z}^{t}, \boldsymbol{w}^{t}\right)}\right]^{1 / 2}
$$

Then, Malmquist cost productivity change (MCP) is defined as:

$$
M C P_{t}^{t+1}=C E F F C H_{t}^{t+1} \cdot C T E C H_{t}^{t+1}=\left[\frac{C^{t}\left(x^{t+1}, z^{t+1}, \boldsymbol{w}^{t+1}\right)}{C^{t}\left(\boldsymbol{x}^{t}, \mathbf{z}^{t}, \boldsymbol{w}^{t}\right)} \frac{C^{t+1}\left(\boldsymbol{x}^{t+1}, \mathbf{z}^{t+1}, \boldsymbol{w}^{t+1}\right)}{C^{t+1}\left(\boldsymbol{x}^{t}, \mathbf{z}^{t}, \boldsymbol{w}^{t}\right)}\right]^{1 / 2} \cdot \frac{c^{t}}{c^{t+1}}
$$

Finally, we define the allocative change as:

$$
A E F F C H_{t}^{t+1}=\frac{A E^{t+1}}{A E^{t}}=\frac{\left(1+D^{t+1}\left(\boldsymbol{x}^{t+1}, \boldsymbol{y}^{t+1}, \mathbf{z}^{t+1}\right)\right) c^{t+1}\left(\boldsymbol{x}^{t+1}, \mathbf{z}^{t+1}, \boldsymbol{w}^{t+1}\right)}{\left(1+D^{t}\left(\boldsymbol{x}^{t}, \boldsymbol{y}^{t}, \mathbf{z}^{t}\right)\right) C^{t}\left(\boldsymbol{x}^{t}, \mathbf{z}^{t}, \boldsymbol{w}^{t}\right)} \cdot \frac{c^{t}}{c^{t+1}}
$$

The indices presented in this section are applied to draw a complete picture of the environmental efficiency change of the power generation industry during the period of restructuring. In the next section, we will discuss how these indices allow comparing power plants with different technologies. To tackle the prevalent infeasibility problem occurs when ML indexes are measured, we employed the method introduced by Arabi et al. (2015).

\subsubsection{Productivity change and non-homogenous power generation technologies}

As it was already addressed in the introduction, in order to the future planning and budgeting, a power industry regulators together with the investors need to be aware of all aspects of the different power generation technologies performance. So it seems not to be comprehensive study if only concentrates on one aspect of the productivity such as efficiency. On the other hand, these types of single dimensional studies convince researchers to categorize the power plants, since technology as a production factor is neglected from the analyses.

In this research, we measure different productivity indexes such as eco-efficiency, cost efficiency, and allocative efficiency to depict which technology has performed better in terms of that particular index. This enables the researcher and policy makers to account for heterogeneity in power generation technologies. This also helps authorities to decide which technology still work and which one can be retired. 


\section{Data}

In this study we take 52, comprising 17 Gas, 18 steam, 9 Combined Cycle, and 8 Hydro Iranian government-owned power plants which are officially connected to Iran national grid before 2003. As it has already been addressed in the present paper, the effects of the restructuring on power plants performance are investigated by observing the effects of changing the rules of the factors of performance measurement. Since two different sets of DEA models, eco-efficiency and cost efficiency, are deployed, the definition of the factors, formula, required data, data source, and the rules related to each factor are presented in technical and cost categories. In Appendix 1 we summarized a number of previous power plant efficiency measurement studies using DEA, this helps us to choose the correct input and output variables. In addition, here we introduce a conceptual approach in order to choose the most proper factors for the power plants eco-efficiency and cost efficiency measurement.

\subsection{Cost and eco-efficiency measurement conceptual model}

Hayman et al. (2008) define Yield Factor as a basic and very simple measure for power plant performance as 'the ratio of energy produced to energy consumed'. This can be interpreted as a simple definition of technical efficiency which is written as below:

$$
T E=\frac{\text { Generated Electricity }}{\text { Fuel }}
$$

where TE stands for technical efficiency. From another perspective power plants technical efficiency can also be measured as:

$$
T E=\frac{\text { Generated Electricity }}{\text { Installed Capacity }}
$$

This ratio can be decomposed as:

$$
T E=\frac{\text { Generated Electricity }}{\text { Operational Availability }} \cdot \frac{\text { Operational Availability }}{\text { Installed Capacity }}
$$

In the right-hand side of Equation (17) denominator is not affected by the restructuring. In the right-hand side of Equation (18) the right fraction is not fully affected by restructuring but in the left ratio, both numerator and denominator can be altered by the restructuring implications. Therefore, in addition to the generated electricity, fuel and installed (effective) capacity as a proxy 
for capital, we take operational availability as an output. Moreover, deviation from generation plan is added to the model since operational availability is declared by the power plants owner to dispatching unit and deviation from generation plan shows whether the power plant can generate as much as declared or not. Furthermore, to see the inverse effect of the power plant on the environment, the emission is also incorporated as a bad output into the model. Table A (see Appendix A) presents a brief literature review confirming the selection of input and output variables in this study. So the eco-efficiency (the technical efficiency) model can be depicted as follows:

[Figure 2 - about here]

Similarly, we can draw cost efficiency conceptual model as follows:

[Figure 3 - about here]

In the following sections, we define how to calculate each factor.

\subsubsection{Fuel and Fuel costs}

In Iran, gas, gasoil and fuel oil are consumed as fuels in the power plants. There is no coal-fired power plant. Iran holds the second largest natural gas resources in the world after Russia; therefore, natural gas has been determined as the main fuel for the country's thermal power plants. It has also been declared that if in urgent situations a power plant is forced to consume gasoil or fuel oil, which are more expensive than gas, the power plants will be reimbursed for the margin price of gasoil and fuel oil at the end of each year*.

\section{[Figure 4 - about here]}

As shown in Figure 4, for the sake of unification, calorific values of different fuel types are considered in the eco-efficiency (technical efficiency) measurement. These calorific values are identical across the country and if the refining technology changes, the new calorific value will be reported to the Ministry of Energy for the required actions. However, as gas is extracted from three

\footnotetext{
* Executive bylaw for electricity guaranteed purchase mechanism and conditions, subject of clause "b" of Article (9), of fourth, validated by fifth NDP-IR 2003
} 
different resources, there are different calorific values. Similar to gasoil and fuel oil, if the extraction process and/or refining technology cause(s) any changes in the calorific value, the new value will be measured and reported to the Ministry of Energy by National Iranian Gas Company. Yearly fuel consumption data for every power plant has been obtained from Tavanir Company*. The calorific values can also be found on the same website.

It is conventional in cost efficiency measurement to multiply the fuel price by the volume of the fuel consumed to calculate the fuel cost. In Iran, however, a specific module has been envisaged in the restructuring project based on which price signals are sent to power plants helping them minimize their fuel consumption and optimize their generation process. The module works like this: the power plants are surcharged if they consume more than the authorized grid fuel consumption limit and rewarded if they manage to consume lower than the same limit. Therefore, the fuel price is calculated using the following formula:

$$
\begin{aligned}
& E C=G E \cdot((1 / P Y F)-(1 / N G Y F)) /(R G H V) \\
& E F C H=E C .(G L P-R P G P) \\
& R P G P=P G P . R G H V / A V G H V
\end{aligned}
$$

where $E C$ is the Excessive Fuel Use, $G E$ is the generated electricity in a year, $P Y F$ is the power plant yearly Yield Factor (see Table 1), NGYF is the yearly average of national grid Yield Factor, $R G H V$ is the regional gas heating [calorific] value; (see Table 2), EFCH is the excessive consumption charge, GLP is the yearly liberated gas price, $R P G P^{\dagger}$ is the regional power plant gas price (It should be noted that the Iranian natural gas is extracted from four different resources and then supplied to four different regions across the country), $P G P$ is the yearly power plant gas price (see Table 1), and $A V G H V$ is the average of countrywide gas heating [calorific] is calculated using the entries of Table 2. GE, PYF, NGYF, and RGHV are available on the website of Tavanir Company, and GLP and PGP can be found in Iran's Energy Balance Sheet Report, which is an annually published journal. It should be noted that the fuel and fuel cost factors for the hydro power plants are supposed to be zero.

\footnotetext{
* Iran Generation, Transmission, and Distribution Holding Company, http://amar.tavanir.org.ir/en/

$\dagger$ In Iran there is different gas prices for different use, also liberated means the unsubsidized gas price
} 


\section{[Table 1 - about here]}

\section{[Table 2 - about here]}

\subsubsection{Capital (effective capacity)}

As it can be observed in Appendix A, in the majority of previous studies, researchers have used the installed capacity as a proxy for the capital input. However, because the installed capacity remains constant for several years in most of the cases and the power plant capital is affected by some factors such as depreciation, overhauls, and even the power plant market value, the installed capacity cannot be a proper surrogate for the capital. Therefore, some researchers such as Yaisawarng and Klein (1994), tried to simulate the capital by the Handy-Whitman Electric Plant Price Index. Nevertheless, they, too, had to use the nameplate capacity and multiplied it by 1973 dollars (the cost of $1 \mathrm{KW}$ of installed capacity). Shanmugam and Kulshreshtha (2005) introduced another formula to estimate the capital: CAPITAL $=(S \times T) / 10^{3}$, where $S$ is the installed plant capacity in $M W$, and $T$ is the number of hours in a year. However, as it can be seen again, this measure is almost a linear function of the installed capacity. As a result, we use the effective capacity as a better proxy for the installed capacity in this study. By definition, effective capacity is an empirical function of the aging factor, ambient temperature, and altitude*. This factor is evaluated yearly and renewed when a power plant undergoes an overhaul. Therefore, the effective or operational capacity of a power plant can be a more accurate proxy for the capital ${ }^{\dagger}$. In Figure 5 a clear growth for both factors can be observed.

\section{[Figure 5 - about here]}

\subsubsection{Depreciation}

We take depreciation as the cost of capital used by a power plant. The data for this factor has been collected the power plant owners. In Iran, the regional electricity companies are the owners of the governmental power plants. In order to evaluate the capital cost of a power plant for further incorporation in the cost efficiency measurements, book values of the country's power plants are

\footnotetext{
* http://www2.tavanir.org.ir/info/stat84/sanatfhtml/page17.htm

${ }^{\dagger}$ ISIRI 13375 1st. Edition http://www.isiri.org/Portal/Home/
} 
reevaluated every 10 years. The corresponding depreciation is evaluated by power plant owners at the end of each fiscal year*.

\subsubsection{Operational Availability}

Still another important factor is operational availability, which is defined as the average yearly electricity, which can be generated during the daily peak hour, as declared by the power plant management to the national dispatching unit. Generated electricity is encouraged to be increased by the power market mechanisms, and enhancement of operational availability is of the power plant owners' interest due to the capacity payment ${ }^{\dagger}$ reasons. The data on the operational availability of the power plants are recorded by the country's national dispatching unit.

\section{[Figure 6 - about here]}

Figure 6 depicts that the reserve margin in peak hours have increased during the eight-year restructuring period since in spite of the installed capacity growth (Figure 5), the ratio of the generated electricity to the installed capacity has dropped. It can also be seen that the ratio of the generated electricity to operational availability has increased despite the fluctuations in the graph.

\subsubsection{Electricity Generated}

This factor, as one of the most common factors, is incorporated in every performance measurement study. Besides, one of the good outputs in the present study is defined as the yearly electricity generated by every power plant in Mega Watt Hours. Data for this factor are also available on the Website of Tavanir Company.

\subsubsection{Emission and Emission cost}

In this study, SO2 has been considered a proxy for all gases emitted. This gas is also a major cause of acid rains and has a predominant role in human respiratory diseases. The data on $\mathrm{SO} 2$ emission have been acquired from Tavanir Environmental Affairs Bureau. Therefore, emission is signified by the yearly $\mathrm{SO} 2$ produced by each power plant in tons.

[Figure 7 - about here]

\footnotetext{
* The depreciations are evaluated using the revised table of the Article 151 of Direct Taxes Act ratified in 2002.

$\dagger$ In Iran, power plants are paid for their availability (Capacity Payment) which is declared by themselves to Iran Grid Management Company (IGMC), they also are charged if they cannot generate as much as they declared.
} 
As observed in Figure 7, the power industry has not succeeded in controlling the fuel type used originally meant to control the emissions consequently. In addition, SO2 emission growth rate has been more than generated electricity growth rate during 2003-2007 however, this rate has been less than generated electricity growth rate during 2008-2010 in average.

A number of rules and regulations have been ratified in Iran to control the industrial emissions. The most important of such legislations is the executive bylaws of Paragraph (C) of Articles 104 and 134 of the Third NDP-IR (2001). Although in this executive bylaw the mechanism for calculation and levying emission charges have been declared, these charges are not imposed in practice because all power plants are governmental, their operation, maintenance and optimization budgets are not large enough and there is no specific budget allocated to apply abatement technologies to the power generation industry. Consequently, no price signal is sent to the power plants to warn them about their emissions. Thus, we adapted the models using two different approaches. The first approach deals with the problem from a power generation industry point of view. In this case, the cost of emission is presumed to be zero since the power plants are not supposed to pay any charges for the emissions produced. The second approach deals with the problem from a national perspective as there are social costs incurred by the society as a result of the emissions. These social costs of each emission type can be obtained from the Iranian Yearly Energy Balance Sheet Journal.

\subsubsection{Deviation from generation plan and Deviation Charges}

As addressed in Section 0, the power plants must declare to the dispatching unit their available capacity. This availability is affected by their operation and maintenance programs, contingencies or even mismanagement and human faults. Therefore, deviations from the generation plan are calculated by the yearly summation of actual energy generated minus the declared available capacity during the daily peak hour. This ratio will be multiplied by zero if the related contingency is not due to mismanagement or human faults. 
If power plants fail to generate as much as they declared to the dispatching unit, they are charged based on the rate of deviation*. The formula for calculation can be briefly written as below:

$$
\begin{aligned}
& D e v_{d}^{t}=(D A C-G E) \cdot B R C P \cdot C H M \\
& D e v^{t}=\sum_{d} D e v_{d}^{t}
\end{aligned}
$$

where:

$D e v_{d}^{t}=$ Deviation from the generation plan (declared available capacity) on the day $d$ of the period $t$

$D A C=$ Declared available capacity

$G E=$ Actual energy generated

$B R C P=$ Basic rate for capacity payment ${ }^{\dagger}$

$C H M=$ Charge multiplier which is 20 or 25 , depending on the type of deviation

$D e v^{t}=$ Deviation charges of the year $t$

Deviation Charge Multiplier $(D C M)=B R C P . C H M$

$D e v^{t}$ is incorporated in cost efficiency measurement models.

[Figure 8 - about here]

Figure 8 exhibits the relationship between charge signals sent to the power plants and the ratio of the deviations to the electricity generated. Except for 2008, DCM shows growth, but the charges have not been significant enough for power plant to make them avoid further deviations. However, in 2009, DCM was dramatically increased by the regulator. This became a major cause of the decrease in deviations from 2009 onward.

\footnotetext{
* This charge is calculated and imposed based on the Executive Bylaw for the Guaranteed Electricity Purchase Mechanism and Conditions, subject of Clause " $b$ " of Article (5), of the fourth, validated by the Fifth NDP-IR, and its attachment as well as the procedure attached to the $20^{\text {th }}$ and $22^{\text {nd }}$ minutes of the Iranian Power Market Regulatory Board, July and August 2004.

${ }^{\dagger}$ Basic rate for capacity payment is calculated based on the market energy price, reserve margin of each day of a year, temperature of the day and whether it is a working day or holiday, procedures attached to minutes $22,45,61,78,88$, 92 and executive bylaw for electricity guaranteed purchase mechanism and conditions, subject of clause "b" of Article (25), of fourth, validated by fifth NDP-IR.
} 


\section{Results and discussions}

\subsection{DEA results and their explanations}

In this paper, we customized Model (7) in the following fashion to use for measuring ecoefficiency:

$$
\begin{array}{ll}
D o(x, y, z)=\max \frac{\sum_{l=1}^{L} \alpha l_{l}+\sum_{h=1}^{H} \alpha h_{h}}{L+H}+\sum_{m=1}^{M} \alpha_{m}+\sum_{k=1}^{K} \gamma_{k} \\
\text { s.t. } & l=1,2, \ldots, L \\
\sum_{n=1}^{N} \lambda_{n} x l_{l n} \leq x l_{l o}+\alpha l_{l} .1 & m=1,2, \ldots, H \\
\sum_{n=1}^{N} \lambda_{n} x h_{h n} \leq x h_{h o}-\alpha h_{h} .1 & h=1,2, \ldots, M \\
\sum_{n=1}^{N} \lambda_{n} x_{n} \leq x_{m o}-\alpha_{m} .1 & \\
\sum_{l=1}^{L} \alpha l_{l}-\sum_{h=1}^{H} \alpha h_{h}=0 & j=1,2, \ldots, J \\
\sum_{n=1}^{N} \lambda_{n} y_{j n} \geq y_{j o} & k=1,2, \ldots, K \\
\sum_{n=1}^{N} \lambda_{n} z_{k n}=z_{k o}-\gamma_{k} .1 & n=1,2, \ldots, N \\
\lambda_{n} \geq 0 & l=1,2, \ldots, L ; h=1,2, \ldots, H \\
\alpha l_{l} \geq 0 ; \alpha h_{h} \geq 0 & m=1,2, \ldots, M ; k=1,2, \ldots, K \\
\alpha_{m} \geq 0 ; \gamma_{k} \geq 0 &
\end{array}
$$

In Model (24), we divide high and low polluting inputs slacks (inefficiencies) by the number of them (here gas, gasoil, fuel oil, making three) in order to leverage the role of fuel inefficiencies in the overall inefficiency. Therefore, in this study we employed Model (24) as a more advanced Model jointly with Equation (10) to measure eco-efficiency. Furthermore, the cost efficiency and allocative efficiency are calculated using Equation (11) which is drawn based on Equation (8) and Model (9).

Using Malmquist and Malmquist Luenberger type indices, we also indicated the trends of the aforementioned productivity measures over the same period. AIMMS 3.12, the student version, was employed to use the models. To measure the eco-efficiency and cost-efficiency, we employed the conceptual models illustrated in the Figure 2 and Figure 3, respectively.

Figure 9 exhibits the average of technical, cost, and allocative efficiency of the different type of power plants. As expected, it can be observed that hydro power plants, on average, have been more eco-efficient than the other technologies, because in this type of power plants no fuel is used, so no emissions are produced obviously. It is true that hydro power plants have been less cost-efficient 
as a result of not use any fuel and producing no emissions; however, enormous investments are required for supplying their electricity generation equipment as well as hydroelectric dam facilities and installations. During the same period, except for the first year, gas technology has proven more cost efficient as it employs smaller and cheaper electricity generation facilities and mostly consumes gas as the main fuel, which contains much lower amounts of sulfur than the other types of fuels do and carries almost zero social costs caused by emissions. Moreover, gas technology has shown a more allocative efficiency, while hydro power plants have been less allocative efficient. A drop in allocative efficiency can be observed from 2003 to 2004. This is due to a growth in the technical efficiency, which has been accompanied by a drop in the cost efficiency in the same period.

\section{[Figure 9 - about here]}

To see the trend of different productivity indexes change, we use $M L, M C P$ and $A L L E F F C H$ indexes to draw the following graphs.

As seen in Figure 10, during the period of restructuring, technical efficiency dropped from 2005 to 2008, while it was controlled afterwards. The allocative efficiency and Malmquist cost efficiency have shown a positive trend in general, except for the cost efficiency in the second and sixth periods and for the allocative efficiency in the first period.

It should be reminded here that as addressed in Section Error! Reference source not found., all the models were developed from a national point of view as well as that of the Ministry of Energy, but as both views (national point of view and that of the Ministry of Energy) showed similar result patterns due to the marginality of the social costs of SO2 in comparison with the other costs mentioned in cost efficiency measurement models we just presented the results obtained from a national point of view incorporating social costs of $\mathrm{SO} 2$.

[Figure 10 - about here] 
Finally, to observe the trends, we also deploy eco-efficiency, cost efficiency and allocative efficiency index as the rate of change and by including their effective capacities; we can calculate the aggregated rate of change for each period, $S_{M L}$, as follows:

$$
S_{p}=\sum_{n=1}^{N}\left(\text { PCI }_{n}^{p} \cdot \text { PEFFCAP }_{n}-P E F F C A P_{n}\right) / \sum_{n=1}^{N} \text { PEFFCAP }_{n}
$$

where:

$P C I_{n}^{p}=$ productivity change index for $n^{\text {th }}$ power plant in a particular period ${ }^{*}$

PEFFCAP $=$ Effective Capacity for $n^{\text {th }}$ power plant in a particular period

$S_{p}=$ Aggregated Rate of productivity change index by Effective Capacity ${ }^{\dagger}$

After calculating each index using Equation (25) we obtain:

As it can be observed in Table 3, although productivity indices show drops in certain periods, all the indices have sustained an overall growth. MLI has dropped during 2005 to 2008, and cost efficiency has shown a downfall in two periods: 2003 to 2005 and 2007 to 2009. However, the allocative efficiency has decreased just in 2004.

\section{[Table 3 - about here]}

\subsection{Discussions}

\subsubsection{Theoretical Issues}

Models (7) and its customized version (24) which are introduced in this study have been successfully deployed to measure the eco-efficiency and eco-efficiency change. Constraint $\sum_{l=1}^{L} \underline{\alpha}_{l}-\sum_{h=1}^{H} \bar{\alpha}_{h}=0$, which guarantees a required amount of fuel is supplied to the power plant to generate a constant level of electricity is a critical constraint. While in the absence of this constraint with the presence of at least one nonpolluting input, the peer efficient DMU can be a DMU with a nonzero output with zero level of fuels, which is impossible. In Model (24) it is also important to leverage the role of fuel in the eco-efficiency measurement. Since in the technical efficiency measurement fuel is just one input, if it is broken down to more different fuel type

\footnotetext{
${ }^{*} P C I^{1}=M L I, P C I^{2}=M C P, P C I^{3}=A E F F C H$

${ }^{\dagger} P=\{M L I, M C P, A E F F C H\}$
} 
inputs, the role of the fuel in the technical efficiency measurement is multiplied by three, which can lead to an inaccurate values of technical efficiency. Here in Model (24) we divide the polluting inputs (inefficiencies) by the number of them.

Furthermore, in this study we introduced Model (11) for the cost efficiency measurement. This model was also successfully deployed to measure the cost efficiency and consequently allocative efficiency. Cost efficiency values and changes in addition to the eco-efficiency and the allocative efficiency values and allow researchers to analyze performance of heterogeneous technologies from different angles. This enables the researcher to make a more defendable judgment about different technologies.

\subsubsection{Empirical Issues}

By reviewing the findings, it can be concluded that restructuring of the Iranian power industry has marginally succeeded in achieving the first and foremost objective, which is improving power generation facility performance. Simultaneously, emissions have been controlled and the ecoefficiency improved. Inauguration of the power market, price liberation, separation of financial and accounting units followed by separation of their managements, and the establishment of power plants as independent power producers have made them be more conservative about their costs, prices, and consumption. These all have led to a series of changes in performance via regular and careful maintenance programs, and in some cases, upgrading the existing technology. Thus, the road to sustainable development will be illuminated before the restructuring leaders and they will be able to continue their efforts. In addition, the results of this study not only will provide a general view of the power plants, which are owned and managed by the government but also $t$ will be useful for the private sector in selecting a proper power plant to purchase, as the power industry reform involves privatization of the power plants, too.

Furthermore, in Section 3.3, we introduced two new models for measurement of eco-efficiency and cost efficiency. These models have been employed to measure the eco-efficiency, cost efficiency and allocative efficiency trends of heterogeneous types of power plants in Iran meant to evaluate the achievements of power industry restructuring in the enhancement of the efficiency of power generation industry. The results reveal that although the hydro power plants have been more eco-efficient, they are less cost efficient. This is while the gas power plants have been more cost and allocative efficient, than other technologies. It has been also shown that during the period of 
restructuring, in spite of incidents such as severe winters, the different indices of efficiency have been relatively enhanced. There is also a requirement for imposing the emission charges and assigning a budget for abatement technologies to control the emissions produced by the power plants; however, determination of gas as the main fuel for the power plants has significantly controlled the emissions produced by the power plants.

\section{Conclusions and Future Studies}

In this paper, we introduced two new models for measurement of eco-efficiency and cost efficiency. These models have been adopted to measure the eco-efficiency, cost efficiency and allocative efficiency trend of heterogeneous types of power plants in Iran to evaluate how successful the power industry restructuring was in enhancing the efficiency of power generation industry. Results reveal that although hydro power plants have been more eco-efficient, they are less cost efficient. In fact, gas power plants proved to be more cost efficient while an almost similar allocative efficiency values were observed for all four technologies. It was also shown that during the period of restructuring, in spite of incidents such as glacial winters, the different indexes of efficiency were enhanced relatively. There is also a requirement for exercising the emission charges and assign a budget for abatement technologies to control the emission produced by the power plants, although the determining natural gas as the main fuel for the power plants significantly decreased the emission produced by the power plants.

For further studies, researchers are encouraged to develop/adopt the efficiency measurement models with liberated price to see what would happen if power plants were obliged to pay real fuel prices. By obtaining hourly generation data of power plants, researchers can evaluate emission charges and then depict and forecast what would happen if emission charges were imposed and how those charges would impact efficiency measures.

\section{Acknowledgments}

Authors would like to express our sincere thanks to Professor Jiri Jaromir Klemes, the editor of Energy, and two reviewers for their constructive comments. As results the papers has been improved substantially. The authors also are grateful to Iran ministry of energy bureau of 
privatization experts for their full support in providing data and information and would like to dedicate this paper to Mr. Jamal Aryayee, the director general of the bureau.

\section{References}

Aghion, P., \& Howitt, P. (1997). Endogenous growth theory: MIT press.

Andersen, P., \& Petersen, N. C. (1993). A procedure for ranking efficient units in data envelopment analysis. Management science, 39(10), 1261-1264.

Arabi, B., Doraisamy, S., Emrouznejad, A., \& Khoshroo, A. (2016). Eco-efficiency measurement and material balance principle: an application in power plants Malmquist Luenberger Index. Annals of Operations Research, 1-19.

Arabi, B., Munisamy, S., \& Emrouznejad, A. (2015). A new slacks-based measure of MalmquistLuenberger index in the presence of undesirable outputs. Omega, 51, 29-37.

Arabi, B., Munisamy, S., Emrouznejad, A., \& Shadman, F. (2014). Power industry restructuring and ecoefficiency changes: A new slacks-based model in Malmquist-Luenberger Index measurement. Energy policy, 68, 132-145.

Athanassopoulos, A. D., Lambroukos, N., \& Seiford, L. (1999). Data envelopment scenario analysis for setting targets to electricity generating plants. European journal of operational research, 115(3), 413-428.

Ball, E., Färe, R., Grosskopf, S., \& Zaim, O. (2005). Accounting for externalities in the measurement of productivity growth: the Malmquist cost productivity measure. Structural Change and Economic Dynamics, 16(3), 374-394.

Banker, R. D. (1984). Estimating most productive scale size using data envelopment analysis. European journal of operational research, 17(1), 35-44.

Banker, R. D., Charnes, A., \& Cooper, W. W. (1984). Some models for estimating technical and scale inefficiencies in data envelopment analysis. Management Science, 30(9), 1078-1092.

Berg, S. A., Førsund, F. R., \& Jansen, E. S. (1992). Malmquist indices of productivity growth during the deregulation of Norwegian banking, 1980-89. The Scandinavian Journal of Economics, 94, 211228. 
Boyd, G. A., \& McClelland, J. D. (1999). The Impact of Environmental Constraints on Productivity Improvement in Integrated Paper Plants. Journal of Environmental Economics and Management, $38(2), 121-142$.

Bulent Tor, O., \& Shahidehpour, M. (2005, 12-16 June 2005). Electric power restructuring in Turkey. Paper presented at the Power Engineering Society General Meeting, 2005. IEEE.

Burnett, R. D., \& Hansen, D. R. (2008). Ecoefficiency: Defining a role for environmental cost management. Accounting, Organizations and Society, 33(6), 551-581.

Charnes, A., \& Cooper, W. (1967). Analítico: Management models and industrial applications of linear programming.

Charnes, A., Cooper, W., \& Rhodes, E. (1978). Measuring the efficiency of decision making units. European journal of operational research, 2(6), 429-444.

Chung, Y. H., Färe, R., \& Grosskopf, S. (1997). Productivity and Undesirable Outputs: A Directional Distance Function Approach. Journal of Environmental Management, 51(3), 229-240.

Cobb, C. W., \& Douglas, P. H. (1928). A theory of production. The American Economic Review, 18(1), 139-165.

Cornwall, J., \& Cornwall, W. (1994). Growth theory and economic structure. Economica, 237-251.

Dyson, R. G., Allen, R., Camanho, A. S., Podinovski, V. V., Sarrico, C. S., \& Shale, E. A. (2001). Pitfalls and protocols in DEA. European journal of operational research, 132(2), 245-259.

Dyson, R. G., \& Thanassoulis, E. (1988). Reducing weight flexibility in data envelopment analysis. Journal of the operational Research Society, 563-576.

Edvardsen, D. F., Førsund, F. R., Hansen, W., Kittelsen, S. A., \& Neurauter, T. (2006). Productivity and regulatory reform of Norwegian electricity distribution utilities. Performance Measurement and Regulation of Network Utilities, 97-131.

Emrouznejad, A., Banker, R., Doraisamy, S. M., \& Arabi, B. (2014, April 12-14). Recent Developments in Data Envelopment Analysis and its Applications. Paper presented at the 12th International Conference of DEA, Kuala Lumpur, Malaysia. 
Emrouznejad, A., \& De Witte, K. (2010). COOPER-framework: A unified process for non-parametric projects. European Journal of Operational Research, 207(3), 1573-1586.

Färe, R., Fukuyama, H., Grosskopf, S., \& Zelenyuk, V. (2015). Decomposing profit efficiency using a slack-based directional distance function. European Journal of Operational Research, 247(1), 335337.

Färe, R., \& Grosskopf, S. (2010a). Directional distance functions and slacks-based measures of efficiency. European journal of operational research, 200(1), 320-322.

Färe, R., \& Grosskopf, S. (2010b). Directional distance functions and slacks-based measures of efficiency: Some clarifications. European journal of operational research, 206(3), 702.

Fare, R., Grosskopf, S., Lindgren, B., \& Roos, P. (1989). Productivity Developments in Swedish Hospitals: A Malmquist Output Index Approach," in A. Charnes, WW Cooper, AY Lewin, and LM Seiford (eds.), Data Envelopment Analysis: Theory, Methodology and Applications, Boston: Kluwer Academic Publishers, 1994.

Färe, R., Grosskopf, S., Noh, D. W., \& Weber, W. (2005). Characteristics of a polluting technology: theory and practice. Journal of Econometrics, 126(2), 469-492.

Färe, R., Grosskopf, S., \& Pasurka, C. A. (2006). Social responsibility: US power plants 1985-1998. Journal of productivity analysis, 26(3), 259-267.

Farrell, M. J. (1957). The measurement of productive efficiency. Journal of the Royal Statistical Society. Series A (General), 120(3), 253-290.

Fried, H. O., Lovell, C. A. K., \& Schmidt, S. S. (2008). Efficiency and productivity, in: Fried, H.O., Lovell, C.A.K., S.S. Schmidt (eds) The Measurement of Productive Efficiency and Productivity Change: New York, Oxford University Press, 3-91. I A.

Fukuyama, H., Masaki, H., Sekitani, K., \& Shi, J. (2014). Distance optimization approach to ratio-form efficiency measures in data envelopment analysis. Journal of Productivity Analysis, 42(2), 175186.

Ghazizadeh, M. S., Sheikh-El-Eslami, M. K., \& Seifi, H. (2007). Electricity restructuring [Business Scene]. Power and Energy Magazine, IEEE, 5(2), 16-20. 
Golany, B., Roll, Y., \& Rybak, D. (1994). Measuring efficiency of power plants in Israel by data envelopment analysis. Engineering Management, IEEE Transactions on, 41(3), 291-301.

Goto, M., \& Tsutsui, M. (1998). Comparison of productive and cost efficiencies among Japanese and US electric utilities. Omega, 26(2), 177-194.

Granderson, G., \& Prior, D. (2013). Environmental externalities and regulation constrained cost productivity growth in the US electric utility industry. Journal of Productivity Analysis, 39(3), 243257.

Han, Y., Geng, Z., Zhu, Q., \& Qu, Y. (2015). Energy efficiency analysis method based on fuzzy DEA crossmodel for ethylene production systems in chemical industry. Energy, 83, 685-695.

Hayman, B., Wedel-Heinen, J., \& Brøndsted, P. (2008). Materials challenges in present and future wind energy. MRS bulletin, 33(4), 343-353.

Jahangoshai Rezaee, M., Moini, A., \& Makui, A. (2012). Operational and non-operational performance evaluation of thermal power plants in Iran: A game theory approach. Energy, 38(1), 96-103.

Jahanshahloo, G. R., Soleimani-damaneh, M., \& Mostafaee, A. (2007). On the computational complexity of cost efficiency analysis models. Applied Mathematics and Computation, 188(1), 638-640.

Khoshroo, A., Mulwa, R., Emrouznejad, A., \& Arabi, B. (2013). A non-parametric Data Envelopment Analysis approach for improving energy efficiency of grape production. Energy, 63, 189-194.

Khosroshahi, K. A., Jadid, S., \& Shahidehpour, M. (2009). Electric Power Restructuring in Iran: Achievements and Challenges. The Electricity Journal, 22(2), 74-83.

Knox Lovell, C. A., Pastor, J. T., \& Turner, J. A. (1995). Measuring macroeconomic performance in the OECD: A comparison of European and non-European countries. European journal of operational research, 87(3), 507-518.

Korhonen, P. J., \& Luptacik, M. (2004). Eco-efficiency analysis of power plants: An extension of data envelopment analysis. European journal of operational research, 154(2), 437-446.

Kurz, H. D., \& Salvadori, N. (1997). Theory of Production: A long-period analysis: Cambridge University Press. 
Lee, S. K., Mogi, G., \& Hui, K. (2013). A fuzzy analytic hierarchy process (AHP)/data envelopment analysis (DEA) hybrid model for efficiently allocating energy R\&D resources: In the case of energy technologies against high oil prices. Renewable and Sustainable Energy Reviews, 21, 347-355.

Li, K., \& Lin, B. (2015). The improvement gap in energy intensity: Analysis of China's thirty provincial regions using the improved DEA (data envelopment analysis) model. Energy, 84, 589-599.

Maniadakis, N., \& Thanassoulis, E. (2004). A cost Malmquist productivity index. European journal of operational research, 154(2), 396-409.

Mazandarani, A., Mahlia, T. M. I., Chong, W. T., \& Moghavvemi, M. (2011). Fuel consumption and emission prediction by Iranian power plants until 2025. Renewable and Sustainable Energy Reviews, 15(3), 1575-1592.

Mostafaee, A., \& Saljooghi, F. H. (2010). Cost efficiency measures in data envelopment analysis with data uncertainty. European journal of operational research, 202(2), 595-603.

Munisamy, S., \& Arabi, B. (2015). Eco-efficiency change in power plants: using a slacks-based measure for the meta-frontier Malmquist-Luenberger productivity index. Journal of Cleaner Production, 105, 218-232.

Ramli, N. A., Munisamy, S., \& Arabi, B. (2013). Scale directional distance function and its application to the measurement of eco-efficiency in the manufacturing sector. Annals of Operations Research, 118.

Sarica, K., \& Or, I. (2007). Efficiency assessment of Turkish power plants using data envelopment analysis. Energy, 32(8), 1484-1499.

Schaltegger, S., \& Sturm, A. (1990). Ökologische rationalität. Die Unternehmung, 4(90), 273-290.

Scott Cato, M. (2009). Green economics: an introduction to theory, policy and practice. London, England, Earthscan Publication, 240p.

Shanmugam, K., \& Kulshreshtha, P. (2005). Efficiency analysis of coal-based thermal power generation in India during post-reform era. International journal of global energy issues, 23(1), 15-28.

Song, M., Song, Y., An, Q., \& Yu, H. (2013). Review of environmental efficiency and its influencing factors in China: 1998-2009. Renewable and Sustainable Energy Reviews, 20(0), 8-14. 
Sueyoshi, T., \& Goto, M. (2011). DEA approach for unified efficiency measurement: Assessment of Japanese fossil fuel power generation. Energy Economics, 33(2), 292-303.

Toloo, M., \& Tichý, T. (2015). Two alternative approaches for selecting performance measures in data envelopment analysis. Measurement, 65, 29-40.

Tone, K. (2001). A slacks-based measure of efficiency in data envelopment analysis. European journal of operational research, 130(3), 498-509.

Tyteca, D. (1997a). Linear programming models for the measurement of environmental performance of firms - concepts and empirical results. Journal of productivity analysis, 8(2), 183-197.

Wang, H. (2015). A generalized MCDA-DEA (multi-criterion decision analysis-data envelopment analysis) approach to construct slacks-based composite indicator. Energy, 80, 114-122.

Yaisawarng, S., \& Klein, J. D. (1994). The Effects of Sulfur Dioxide Controls on Productivity Change in the U.S. Electric Power Industry. The Review of Economics and Statistics, 76(3), 447-460.

Zhou, P., Ang, B. W., \& Poh, K. L. (2006). Slacks-based efficiency measures for modeling environmental performance. Ecological Economics, 60(1), 111-118. 


\section{Appendix}

Table A: A brief summary of inputs and outputs have been incorporated in efficiency/eco-efficiency evaluation of power plants using DEA

\begin{tabular}{|c|c|c|c|c|}
\hline Title & Author/s & Year & Inputs & Outputs \\
\hline $\begin{array}{l}\text { Measuring efficiency } \\
\text { of power plants in } \\
\text { Israel by data } \\
\text { envelopment analysis }\end{array}$ & $\begin{array}{l}\text { Golany, B. } \\
\text { Roll, Y. } \\
\text { Rybak, D. }\end{array}$ & (1994) & $\begin{array}{l}\text { 1. Installed Capacity } \\
\text { 2. Fuel Consumption } \\
\text { 3. Man Power }\end{array}$ & $\begin{array}{l}\text { Undesirable: } \\
\text { 1. SO2 emission } \\
\text { 2. Deviation from operational } \\
\text { parameters } \\
\text { Desirable: } \\
\text { 1. Generated Energy } \\
\text { 2. Operational availability }\end{array}$ \\
\hline $\begin{array}{l}\text { Comparison of } \\
\text { productive and cost } \\
\text { efficiencies among } \\
\text { Japanese and US } \\
\text { electric utilities }\end{array}$ & $\begin{array}{l}\text { Goto, M. } \\
\text { Tsutsui, M. }\end{array}$ & (1998) & $\begin{array}{l}\text { 1. Nameplate generation } \\
\text { capacity } \\
\text { 2. quantity of fuel used } \\
\text { 3. total number of } \\
\text { employees } \\
\text { 4. quantity of power } \\
\text { purchase }\end{array}$ & $\begin{array}{l}\text { Desirable: } \\
\text { 1. quantity sold to residential } \\
\text { customers } \\
\text { 2. quantity sold to non- } \\
\text { residential (commercial, } \\
\text { industrial, others, and } \\
\text { wholesale) customers }\end{array}$ \\
\hline $\begin{array}{l}\text { Data envelopment } \\
\text { scenario analysis for } \\
\text { setting targets to } \\
\text { electricity generating } \\
\text { plants }\end{array}$ & $\begin{array}{l}\text { Athanassopoulos, } \\
\text { A.D. } \\
\text { Lambroukos, N. } \\
\text { Seiford, L. }\end{array}$ & (1999) & $\begin{array}{l}\text { 1. Fuel } \\
\text { 2. Controllable Costs } \\
\text { 3. Capital Expenditure }\end{array}$ & $\begin{array}{l}\text { Undesirable: } \\
\text { 1. Generated pollution } \\
\text { 2. Accidents Incurred } \\
\text { Desirable: } \\
\text { 1. Electricity Produced } \\
\text { 2. Plant availability }\end{array}$ \\
\hline $\begin{array}{l}\text { Eco-efficiency } \\
\text { analysis of power } \\
\text { plants: An extension } \\
\text { of data envelopment } \\
\text { analysis }\end{array}$ & $\begin{array}{l}\text { Korhonen, Pekka } \\
\text { J. } \\
\text { Luptacik, } \\
\text { Mikulas }\end{array}$ & (2004) & Total costs & $\begin{array}{l}\text { Undesirable: } \\
\text { DUST, NOx and SO2 } \\
\text { Desirable: } \\
\text { electricity generation }\end{array}$ \\
\hline $\begin{array}{l}\text { Characteristics of a } \\
\text { polluting technology: } \\
\text { Theory and practice }\end{array}$ & $\begin{array}{l}\text { Färe, R., } \\
\text { Grosskopf, Sh. } \\
\text { Noh, D-W, } \\
\text { Weber, W. }\end{array}$ & $(2005)$ & $\begin{array}{ll}\text { 1. } & \text { Labour } \\
\text { 2. } & \text { Installed capacity } \\
\text { 3. } & \text { Fuel }\end{array}$ & $\begin{array}{l}\text { Undesirable: } \\
\text { 1. SO2 emission } \\
\text { Desirable: } \\
\text { 1. Generated Energy }\end{array}$ \\
\hline $\begin{array}{l}\text { Efficiency } \\
\text { assessment of } \\
\text { Turkish power plants } \\
\text { using data } \\
\text { envelopment analysis }\end{array}$ & $\begin{array}{l}\text { Sarica, K. } \\
\text { Or, I. }\end{array}$ & (2007) & $\begin{array}{l}\text { For Thermal Power } \\
\text { Plants } \\
\text { 1. fuel cost } \\
\text { 2. production } \\
\text { For renewable Power } \\
\text { Plants } \\
\text { 1. Operating costs }\end{array}$ & $\begin{array}{l}\text { Thermal Power Plants } \\
\text { Undesirable: } \\
\text { 1.environmental cost } \\
\text { 2. Carbon monoxide (CO) } \\
\text { Desirable: } \\
\text { 3. availability } \\
\text { 4.Thermal efficiency } \\
\text { Renewable Power Plants } \\
\text { 1.production } \\
\text { 2.utilization }\end{array}$ \\
\hline $\begin{array}{l}\text { Eco-efficiency: } \\
\text { Defining a role for } \\
\text { environmental cost } \\
\text { management }\end{array}$ & $\begin{array}{l}\text { Burnett, R. D. } \\
\text { Hansen, D. R. }\end{array}$ & (2008) & $\begin{array}{ll}\text { 1. } & \text { Capital } \\
\text { 2. } & \text { Fuel costs } \\
\text { 3. } & \text { Operating costs }\end{array}$ & 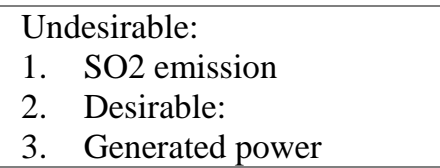 \\
\hline $\begin{array}{l}\text { DEA approach for } \\
\text { unified efficiency } \\
\text { measurement: } \\
\text { Assessment of } \\
\text { Japanese fossil fuel } \\
\text { power generation }\end{array}$ & $\begin{array}{l}\text { Sueyoshi,T. } \\
\text { Goto, M. }\end{array}$ & (2011) & $\begin{array}{ll}\text { 1. } & \text { Generation capacity } \\
\text { 2. Number of } \\
\text { employees } \\
\text { 3. Coal } \\
\text { 4. } \text { Oil } \\
\text { 1. LNG }\end{array}$ & $\begin{array}{l}\text { Undesirable: } \\
\text { 1. CO2 emission } \\
\text { Desirable: } \\
\text { Generation }\end{array}$ \\
\hline
\end{tabular}




\begin{tabular}{|c|c|c|c|c|}
\hline Title & Author/s & Year & Inputs & Outputs \\
\hline $\begin{array}{l}\text { Operational and non- } \\
\text { operational } \\
\text { performance } \\
\text { evaluation of thermal } \\
\text { power plants in Iran: } \\
\text { A game theory } \\
\text { approach }\end{array}$ & $\begin{array}{l}\text { Jahangoshai } \\
\text { Rezaee M., } \\
\text { Moini A, } \\
\text { Makui A. }\end{array}$ & $(2012)$ & $\begin{array}{l}\text { Operational inputs } \\
\text { 1. Generation capacity } \\
\text { 2. Total hours of } \\
\text { operation } \\
\text { 3. Internal consuming } \\
\text { 4. Fuel consumption } \\
\text { Non-operational inputs } \\
\text { 1. No. Nonoperational } \\
\text { employees } \\
\text { 2. No. Operational } \\
\text { employees } \\
\text { 3. Cost of Generated } \\
\text { Energy per kWh } \\
\text { 4. Total cost of training }\end{array}$ & $\begin{array}{l}\text { 1. Total revenue } \\
\text { 2. Total amount of electricity } \\
\text { generated } \\
\text { 3. CO2 emission }\end{array}$ \\
\hline $\begin{array}{l}\text { Eco-efficiency } \\
\text { Change in Power } \\
\text { Plants: Using A } \\
\text { Slack-Based Measure } \\
\text { for the Meta-Frontier } \\
\text { Malmquist } \\
\text { Luenberger } \\
\text { Productivity Index }\end{array}$ & $\begin{array}{l}\text { Munisamy S, } \\
\text { Arabi B }\end{array}$ & (2015) & $\begin{array}{l}\text { 1. Installed Capacity } \\
\text { (Capital) } \\
\text { 2. Fuel }\end{array}$ & $\begin{array}{l}\text { Undesirable: } \\
\text { 1. SO2 emission } \\
\text { 2. Deviation from operational } \\
\text { Plans } \\
\text { Desirable: } \\
\text { 3. Generated Energy } \\
\text { 4. Operational availability }\end{array}$ \\
\hline
\end{tabular}




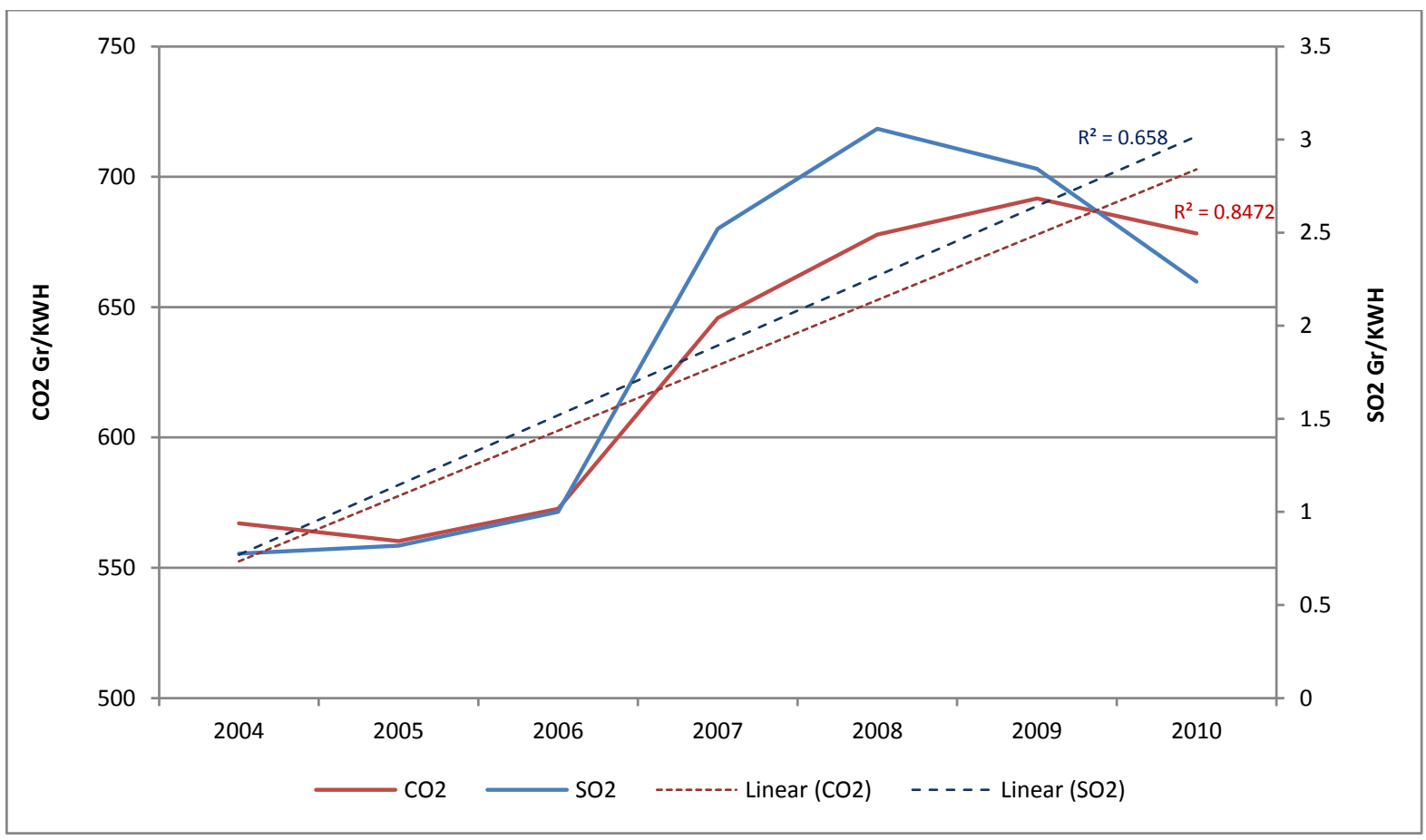

Figure 1: Gr/kWh SO2 and CO2 produced by the Iranian power plants, 2004-2010



Figure 2: Eco-efficiency (technical efficiency) measurement conceptual model 




Figure 3: Cost efficiency measurement conceptual model

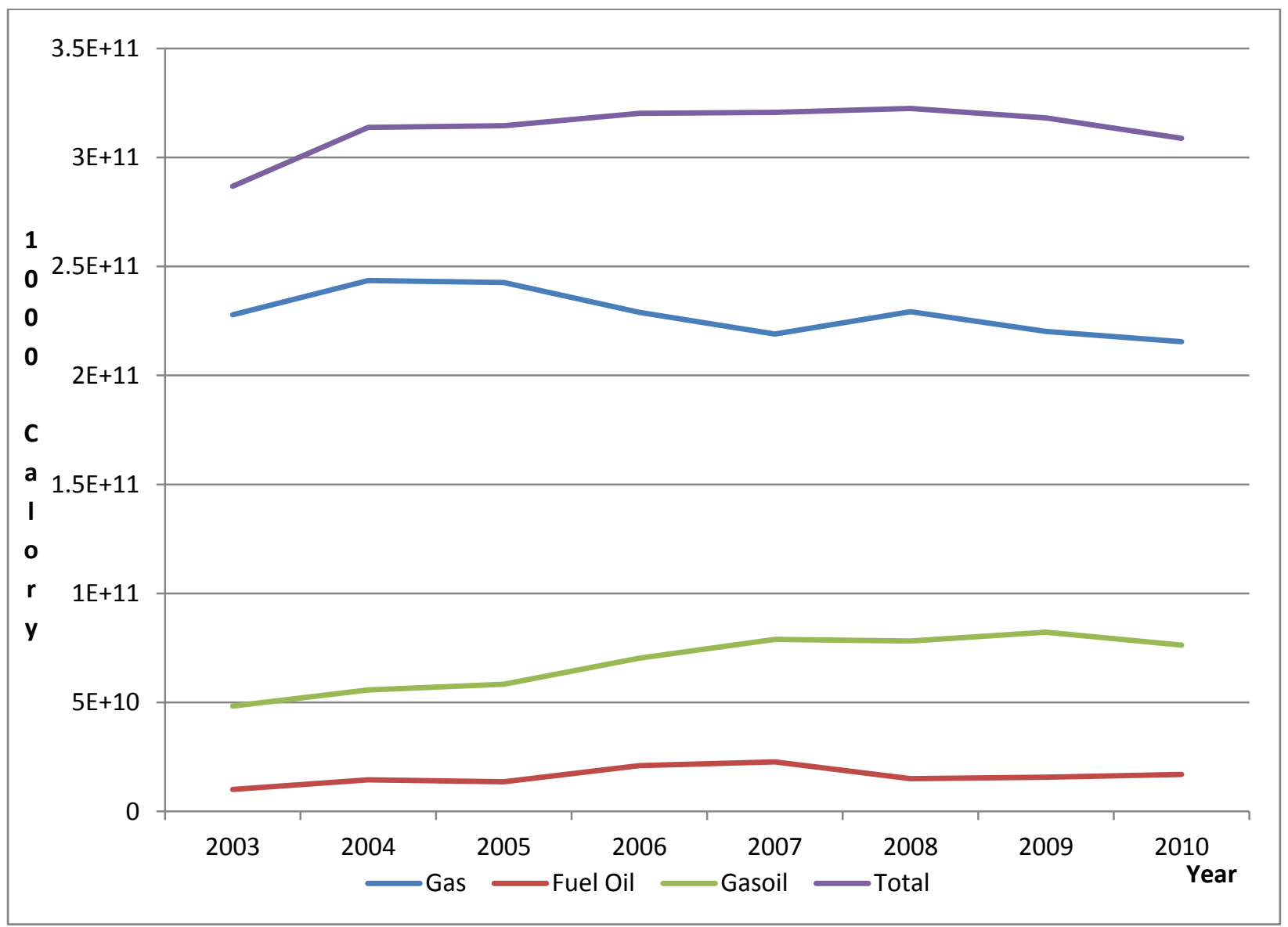

Figure 4: Fuel consumption by the thermal power plants 


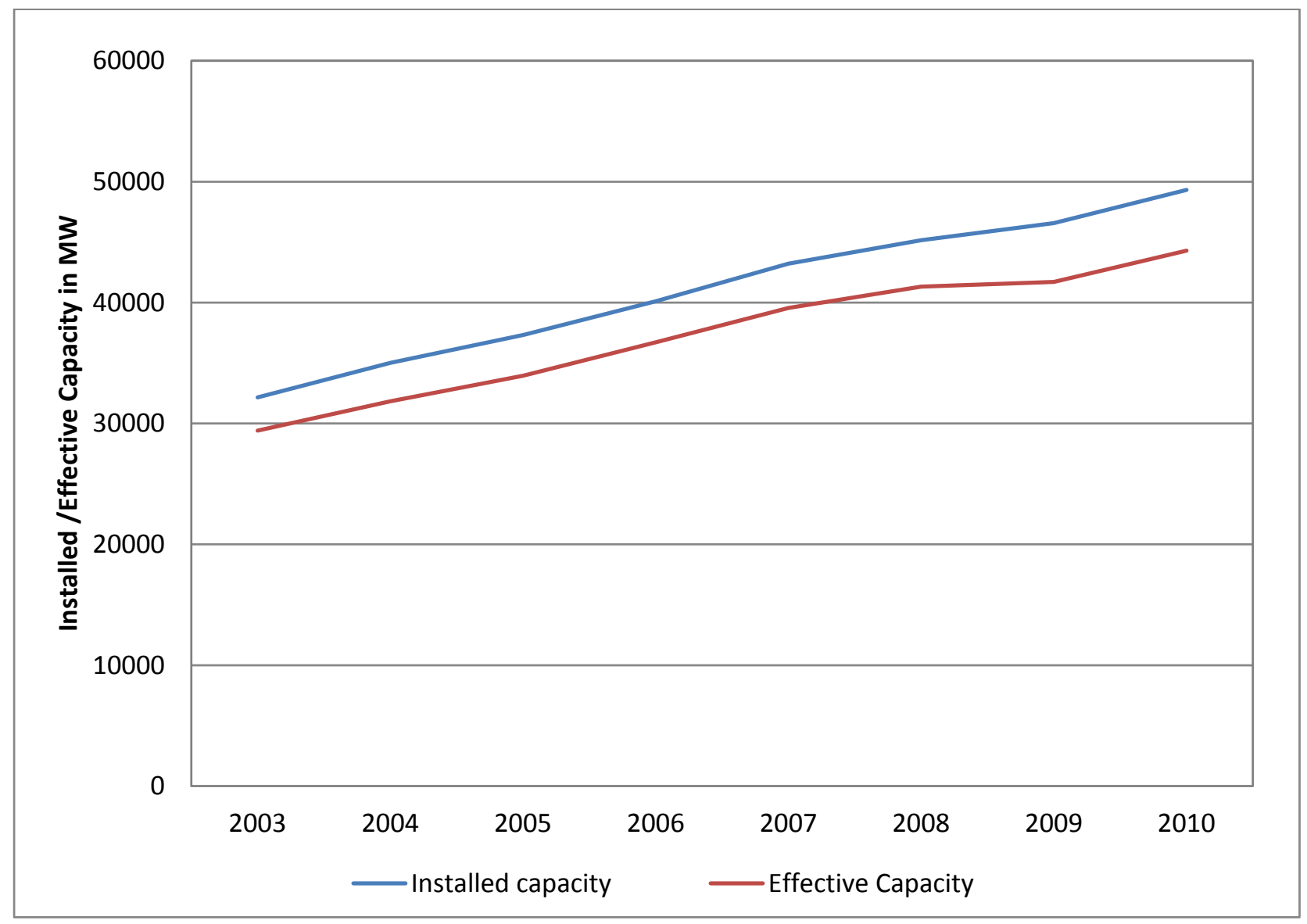

Figure 5: Installed and effective capacity trends 


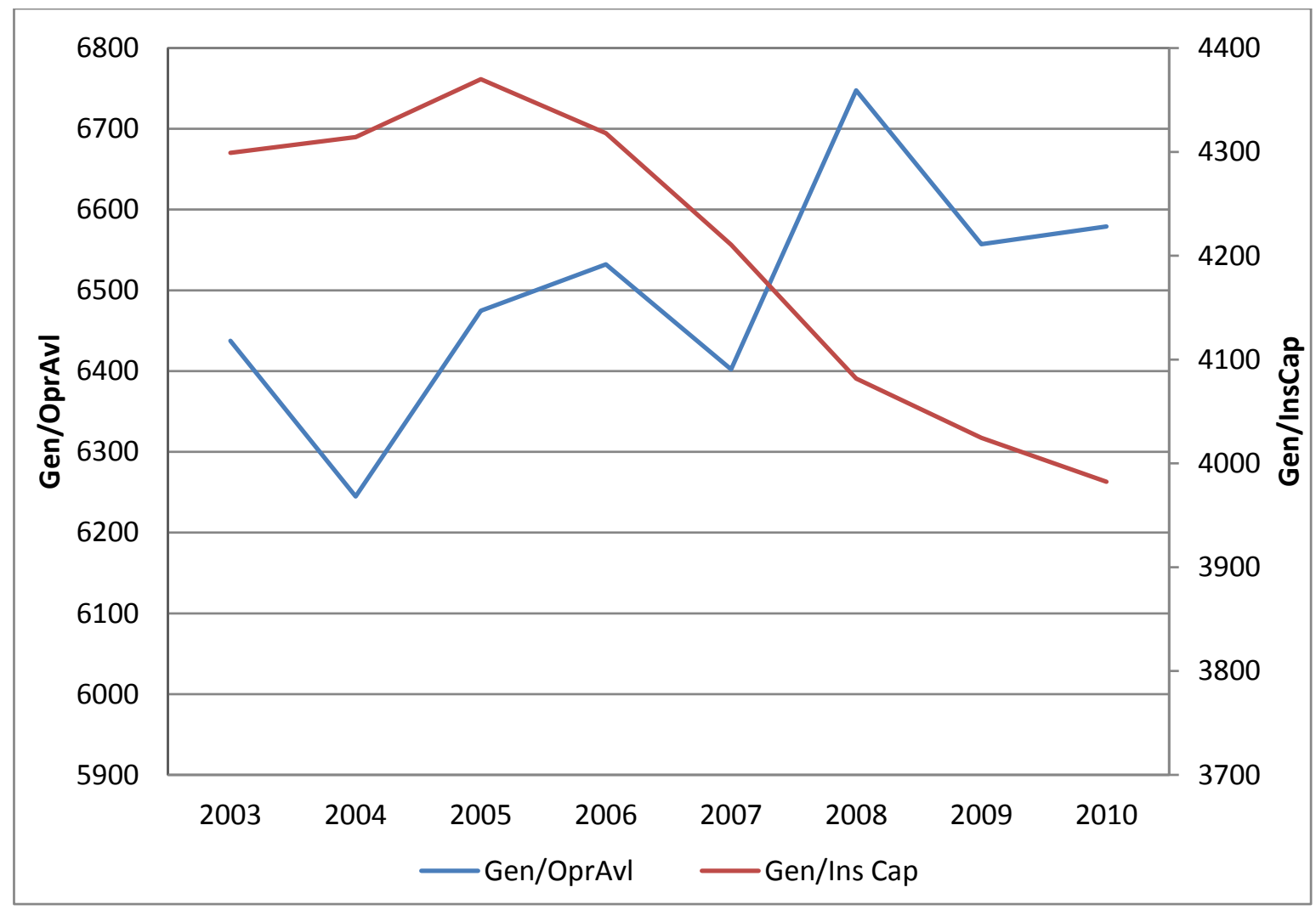

Figure 6: Ratio of generated electricity to operational availability and installed capacity trends 


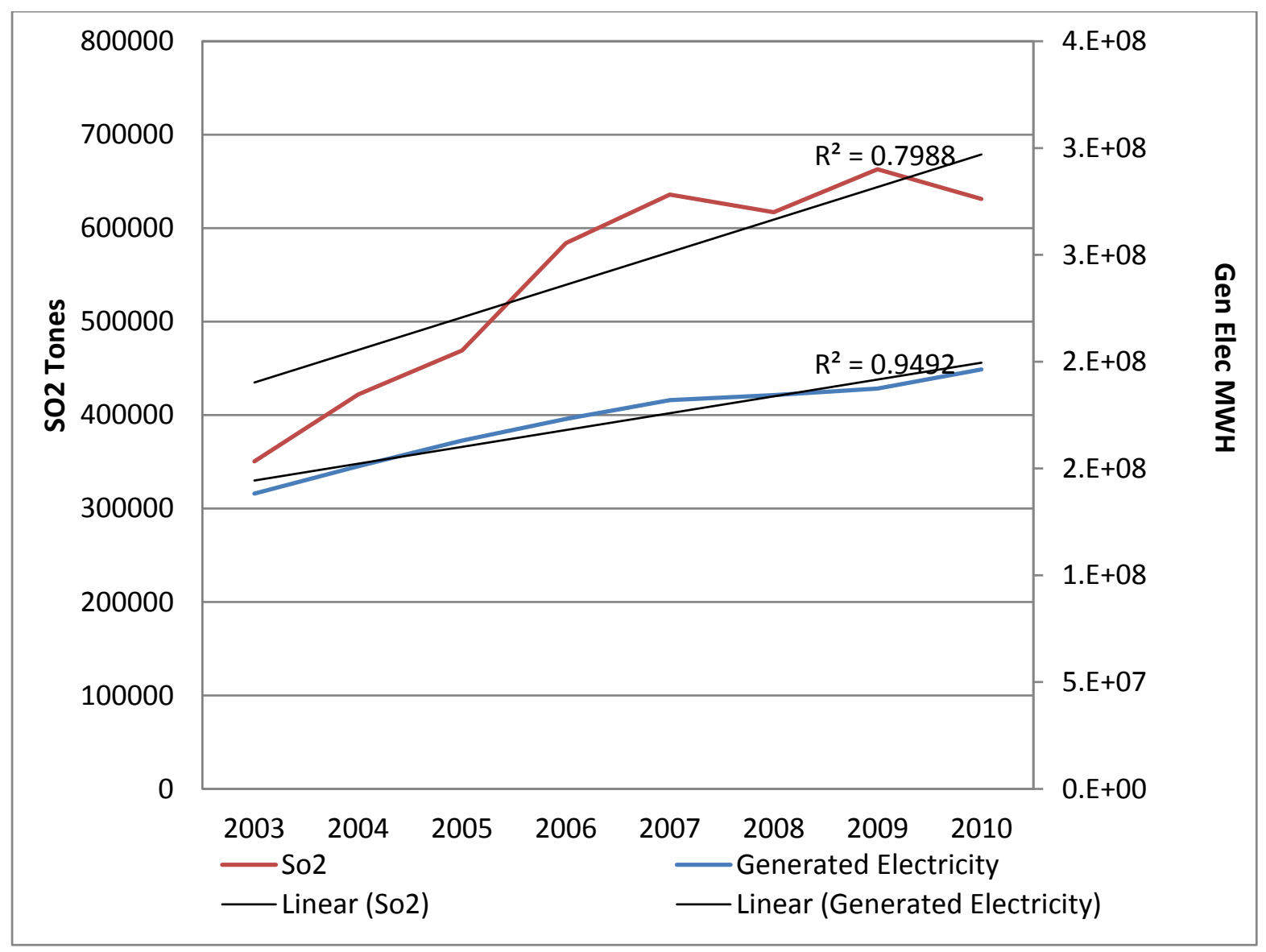

Figure 7: SO2 Produced over generated electricity 




Figure 8: Deviation from generation plan to generated electricity and deviation charge multiplier 

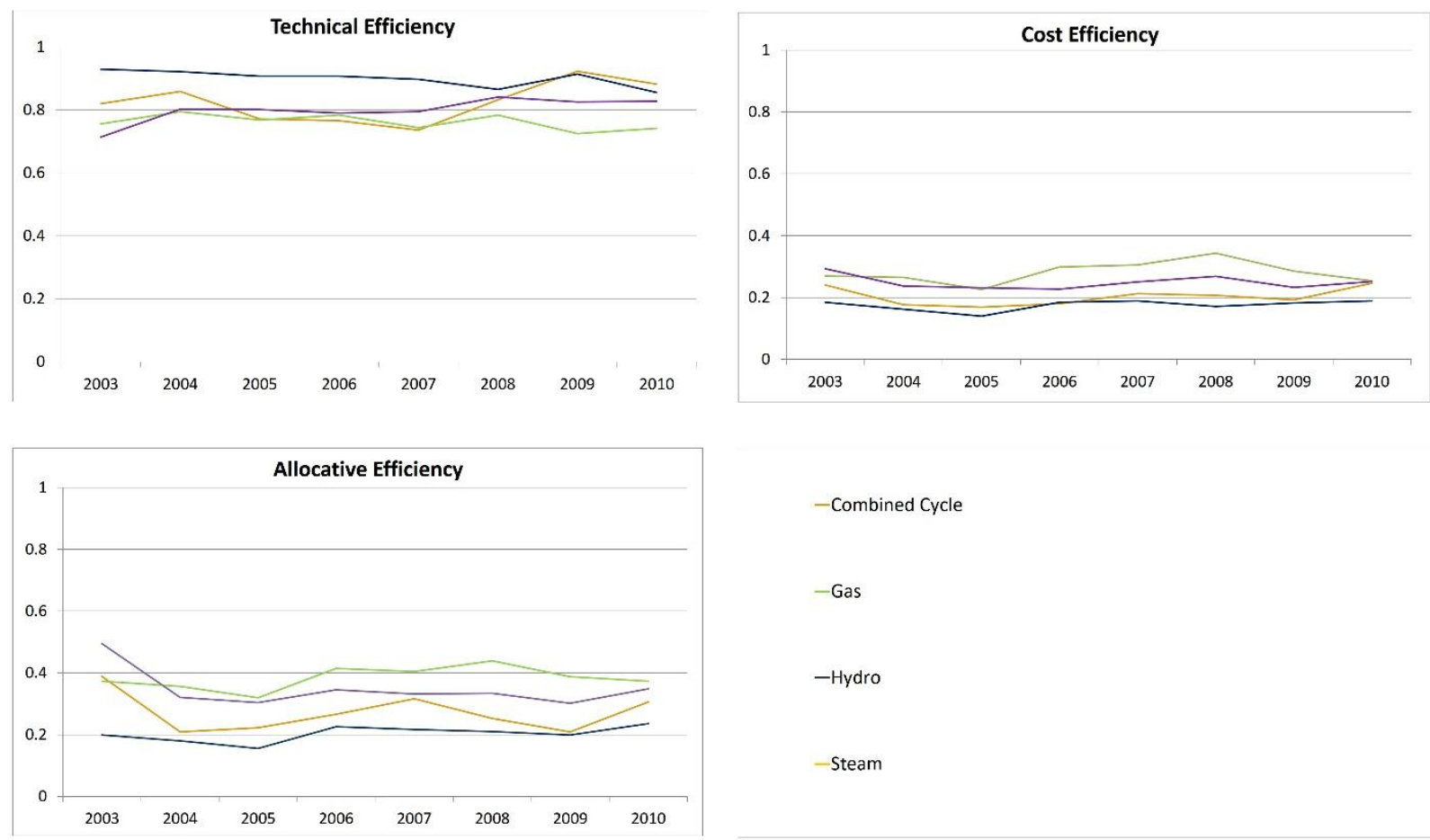

Figure 9: Average technical, cost and allocative efficiency of different types of power plants 

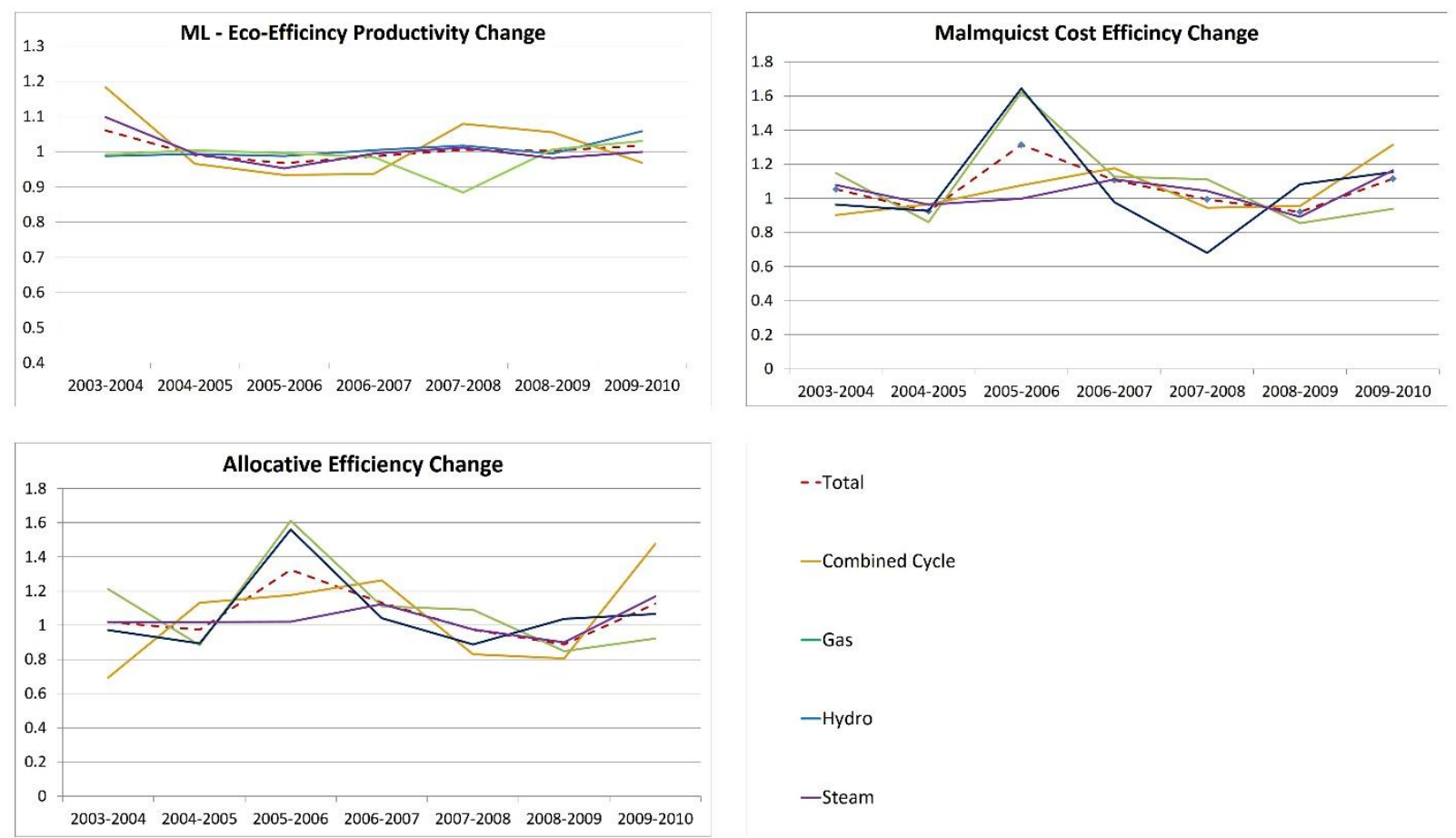

$$
\begin{aligned}
& \text { - -Total } \\
& \text {-Combined Cycle } \\
& \text {-Gas } \\
& \text {-Hydro } \\
& \text {-Steam }
\end{aligned}
$$

Figure 10: ML, MCP, and ALLEFFCH indexes to see productivity change during restructuring period 
Table 1: Required coefficient to calculate fuel and SO2 costs and deviation charges, in Rials

\begin{tabular}{cccccccc}
\hline Year & $\begin{array}{c}\text { Mean Yield } \\
\text { Factor } \\
\text { (Percent) }\end{array}$ & $\begin{array}{c}\text { Liberated } \\
\text { Gas Price } \\
\text { (Rials) }\end{array}$ & $\begin{array}{c}\text { Gas } \\
\text { Price } \\
\text { (Rials) }\end{array}$ & $\begin{array}{c}\text { Gasoil } \\
\text { Price } \\
\text { (Rials) }\end{array}$ & $\begin{array}{c}\text { Fuel Oil } \\
\text { Price (Rials) }\end{array}$ & $\begin{array}{c}\text { Basic Rate for } \\
\text { Capacity Payment } \\
\text { (Rials) }\end{array}$ & $\begin{array}{c}\text { SO2 } \\
\text { Social Costs } \\
\text { (Rials) }\end{array}$ \\
\hline 2003 & 37.2 & 27 & 27 & 27 & 27 & 72000 & 14600 \\
2004 & 36 & 29 & 29 & 29 & 29 & 72000 & 14600 \\
2005 & 37.6 & 29 & 29 & 29 & 29 & 72000 & 14600 \\
2006 & 35.5 & 29 & 29 & 29 & 29 & 72000 & 14600 \\
2007 & 35.8 & 690 & 49 & 49 & 49 & 77000 & 14600 \\
2008 & 36 & 690 & 49 & 49 & 49 & 77000 & 14600 \\
2009 & 36 & 49.3 & 49.3 & 49.3 & 49.3 & 89000 & 14600 \\
2010 & 36.6 & 950 & 793 & 793 & 793 & 89000 & 14600 \\
\hline
\end{tabular}

Table 2: Gas heating value by different resources, Btu/ $\mathrm{M}^{3}$

\begin{tabular}{ccccccccc}
\hline Pipe Line & $\mathbf{2 0 0 3}$ & $\mathbf{2 0 0 4}$ & $\mathbf{2 0 0 5}$ & $\mathbf{2 0 0 6}$ & $\mathbf{2 0 0 7}$ & $\mathbf{2 0 0 8}$ & $\mathbf{2 0 0 9}$ & $\mathbf{2 0 1 0}$ \\
\hline 1 & 8210 & 8614 & 8614 & 8614 & 8614 & 8486 & 8486 & 8486 \\
2 & 8590 & 8664 & 8664 & 8664 & 8664 & 8541 & 8541 & 8541 \\
3 & 9355 & 8779 & 8779 & 8779 & 8779 & 8642 & 8642 & 8642 \\
4 & $\mathrm{n} / \mathrm{a}$ & 8793 & 8793 & 8793 & 8793 & 8763 & 8763 & 8763 \\
5 & $\mathrm{n} / \mathrm{a}$ & 9099 & 9099 & 9099 & 9099 & n/a & n/a & n/a \\
\hline
\end{tabular}

Here n/a means the pipeline has not been used for gas delivery to the power plants

Table 3: $S_{p}$ index values

\begin{tabular}{ccccccccc}
\hline & $2003-$ & $2004-$ & $2005-$ & $2006-$ & $2007-$ & $2008-$ & $2009-$ & \multirow{2}{*}{ Grand Total } \\
& 2004 & 2005 & 2006 & 2007 & 2008 & 2009 & 2010 & \\
\hline$M L I$ & 0.00354 & 0.000030 & -0.00112 & -0.00032 & -0.001582 & 0.00056 & 0.000168 & 0.001277 \\
$M C P$ & -0.00042 & -0.00122 & 0.00531 & 0.00202 & -0.000697 & -0.001125 & 0.004232 & 0.008096 \\
\multirow{2}{*}{ AEFFCH } & -0.001944 & 0.0092081 & 0.0018365 & 0.0017875 & 0.0003104 & 0.0008455 & 0.002378 & 0.014422 \\
\hline
\end{tabular}

